\title{
Supplementary Information for \\ Autocatalysis and Oriented Attachment Direct the Synthesis of Metal-Organic Framework
}

\author{
Anish V. Dighe ${ }^{1, \$}$, Luke Huelsenbeck ${ }^{2,}$, Rajan R. Bhawnani ${ }^{1}$, Prince Verma ${ }^{2}$, Kevin H. Stone $^{3}$, \\ Meenesh R. Singh ${ }^{1, *}$, and Gaurav Giri ${ }^{2, *}$ \\ ${ }^{1}$ Department of Chemical Engineering, University of Illinois at Chicago, Chicago, IL 60607, \\ United States \\ ${ }^{2}$ Department of Chemical Engineering, University of Virginia, Charlottesville, Virginia 22903, \\ United States \\ ${ }^{3}$ Stanford Synchrotron Radiation Lightsource, SLAC National Accelerator Laboratory, Menlo \\ Park, CA, 94025, United States \\ $\$$ Authors contributed equally
}

\section{Corresponding Authors:}

Prof. Meenesh R. Singh

Assistant Professor

Department of Chemical Engineering 929 W. Taylor St

University of Illinois at Chicago

Chicago, IL 60607

Tel: (312) 996-3424

Email: mrsingh@uic.edu
Prof. Gaurav Giri

Assistant Professor

Department of Chemical Engineering

102 Engineers' Way

University of Virginia

Charlottesville, Virginia 22903

Tel: 434-924-1351

Email:gg3qd@virginia.edu

Keywords: Autocatalysis, Oriented Attachment, Chain Growth, Step Growth, In-situ X-Ray Scattering 


\section{Section S1: Experimental Methods}

\section{Materials}

All reagents were used as received with no further purification. Zirconium (IV) propoxide solution (70 wt\% in 1-propanol, Sigma Aldrich), acetic acid (Glacial, Sigma Aldrich), and N,N dimethylformamide (DMF, 99.8\%, Sigma Aldrich) were used to synthesize a node solution. Terephthalic acid $\left(\mathrm{H}_{2} \mathrm{BDC}\right.$, 98\%, Sigma Aldrich) and N,N dimethylformamide (DMF, 99.8\%, Sigma Aldrich) were used to prepare the linker solution. Graphite (powder, $<20 \mu \mathrm{m}$, synthetic, Sigma Aldrich) was used in the nucleation type study.

\section{UiO-66 Synthesis}

The synthetic procedure was adapted from work by Farha et al. ${ }^{1}$ A zirconium oxo cluster node stock solution was prepared by mixing $142 \mu \mathrm{L}$ of Zirconium (IV) propoxide in a mixture of $4 \mathrm{~mL}$ of acetic acid and $7 \mathrm{~mL}$ of DMF in a $20 \mathrm{~mL}$ scintillation vial. The solution was wrapped in foil and heated on a hotplate at $155{ }^{\circ} \mathrm{C}$ for 2.25 hours and resulted in a pale-yellow solution then allowed to naturally cool to room temperature. Linker solution was prepared by mixing $0.271 \mathrm{~g}$ of $\mathrm{H}_{2} \mathrm{BDC}$ in $5 \mathrm{~mL}$ of DMF until fully dissolved. Both solutions were used as stock for the experiment series. The experimental setup to run the reaction has been illustrated in Figure S1. For a typical synthesis, $5 \mathrm{~mL}$ of zirconium node solution was placed in a custom glass reactor along with 4.5 $\mathrm{mL}$ of fresh DMF and a stir rod. $0.5 \mathrm{~mL}$ of linker solution was loaded into a computer-controlled syringe pump precalibrated for injection volume, with injection tubing placed just above the surface of the reaction solution. The lower linker solution volume was used to ensure temperature was constant for the bulk solution at higher temperature conditions. The temperature was controlled via a thermocouple placed in the reactor and heating tape wrapped around the reactor. The solution was stirred at $300 \mathrm{rpm}$ to ensure a slight vortex was noticeable on the solution surface but not entraining air. The reactor was secured and aligned with the x-ray beam by maximizing count intensity in the dimensions defining a normal plane to the beam (Figure S2). The reaction was initiated by rapidly injecting the desired quantity of linker solution into the stirred metal solution, with subsequent data collection initiating with the same computer-controlled command. Concentration was varied by adjusting the initial amount of metal solution in the reactor, or the quantity of linker solution injected with volumes held constant by the addition of solvent (DMF or a DMF/acetic acid mixture).

\section{In Situ Wide Angle X-ray Scattering (WAXS) Experiments}

In situ WAXS experiments were performed at beamline 10-2 in the Stanford Synchrotron Radiation Lightsource (SSRL) at SLAC National Laboratory (Menlo Park, California) with a beam energy of $17 \mathrm{keV}$. Two-dimensional patterns were recorded at 1 second exposure times with an Eiger 1M Hybrid Photon Counting (HPC) detector (Eiger) with a sample to detector distance of 1 $\mathrm{m}$. A custom-blown glass reactor with a $\sim 0.5 \mathrm{~cm}$ solution X-ray pathlength was used to run each synthesis. Linker solution injection and data collection were synchronized via computer control. The temperature was controlled using a thermocouple submerged in the reaction solution and a heating tape surrounding the reactor. The reactor was scrubbed with soap and water, then sonicated and rinsed with DI water and acetone after each reaction. 


\section{WAXS Data Analysis}

WAXS data was reduced and analyzed with a Python script with the pyFAI module. After background subtraction, peaks were fit with Gaussian curves to determine curve area and FWHM for each frame for the (111) and (222) peaks. The resulting values were exported as raw data to calculate the extent of crystallization and coherence length, respectively. The extent of crystallization was determined by fitting the Gualtieri model with a normalization constant to determine the extent of crystallization as a function of time (derivation shown below). The measured intensity is linearly related to the volume fraction of the crystalline phase for a given diffraction peak. Thus the extent of crystallization is linearly related to crystalline volume fraction. ${ }^{2}$ Such a technique has been used for in situ tracking and quantitative analysis for UiO-66 and other common MOFs, ${ }^{3,4,5,6}$ with an exhaustive list provided by Schmidt et al. ${ }^{7}$ 


\section{Section S2: Features of Sigmoidal Curve}

The sigmoidal curves in reaction kinetics are common in homogeneous and heterogeneous catalysis as well as enzyme-catalyzed biochemical reactions and usually represent product formation as a function of time. Figure $\mathbf{S 3}$ shows the features of the sigmoidal curve. The sigmoidal curve has four distinct features:

(1) Induction Phase:

The induction phase occurs at the initial times where the catalytic reaction is limited by the mass transport due to the geometry of the reactor or due to the diffusion of the reactants to the catalytic site. The slope of the product formation curve during this phase is close to zero.

(2) Exponential Growth Phase:

The exponential growth phase occurs due to excessive concentration of catalytic sites for the product formation. During this phase, the slope of the tangent as a function of time is almost linear, indicating that the rate of product formation depends strongly on the rate constant of the product formation reaction.

\section{(3) Transition Phase:}

The termination phase begins when the catalytic sites are saturated, and the concentration of the reactants in the solution is depleted due to the exponential growth phase. During this phase, the slope of the tangent is sub-linear, indicating that the rate of product formation is dependent upon the rate constant as well as the reactant concentration.

(4) Stationary Phase:

Steady-state occurs due to complete consumption of reactants in the solution, and the rate of product formation approaches zero. 


\section{Section S3: Computational Methods}

\section{Theoretical Model of MOF Formation}

In this model, the first step is the formation of a growth unit, and the next step is the aggregation of growth units to form higher-order clusters. The rate equations assume Flory's approximation ${ }^{8}$ of the polymer chain and step additions. The reaction scheme is shown below.

$$
\begin{array}{ll}
m M+l L \stackrel{k_{1}}{\longrightarrow} P_{1} & r_{1}=k_{1}[M]^{a}[L]^{b} \\
P_{1}+P_{1} \stackrel{k_{2}}{\longrightarrow} P_{2} & r_{11}=k_{2}\left[P_{1}\right]^{2} \\
\cdot & \\
P_{n-1}+P_{1} \stackrel{k_{2}}{\longrightarrow} P_{n} & r_{n-1,1}=k_{2}\left[P_{n-1}\right]\left[P_{1}\right] \\
P_{2}+P_{2} \stackrel{k_{3}}{\longrightarrow} P_{4} & r_{22}=k_{3}\left[P_{2}\right]\left[P_{2}\right] \\
\cdot & \\
P_{n-2}+P_{2} \stackrel{k_{3}}{\longrightarrow} P_{n} & r_{n-2,2}=k_{3}\left[P_{n-2}\right]\left[P_{2}\right] \\
\cdot & \\
P_{j}+P_{i} \stackrel{k_{i+1}}{\longrightarrow} P_{j+i} & r_{j i}=k_{i+1}\left[P_{j}\right]\left[P_{i}\right] \\
\cdot & \\
P_{n-i}+P_{n_{k}} \stackrel{k_{n_{k}+1}}{\longrightarrow} P_{n} & r_{n-i, n k}=k_{n_{k}+1}\left[P_{n-i}\right]\left[P_{n k}\right]
\end{array}
$$

In the reaction scheme above, $m$ and $l$ are the stoichiometric coefficients of the metal-ligand $M$ and organic linker $L$ required for the formation of the smallest growth unit $P_{1} . P_{h}$ is an oligomer consisting $h$ number of smallest growth units (or monomers). $i=1,2, \ldots, n_{k}$ where $n_{k}$ is the largest growth unit that can undergo aggregation to form further higher-order growth units and $j=i, i+1, \ldots, n-i$ are all the possible growth units that undergo aggregation due to growth units $P_{i} . n$ is the largest size of the growth unit possible due to aggregation. The concentration of all components is in the units of $\mathrm{mol} \mathrm{L}^{-1} . k_{1}$ is the rate constant for the reaction of formation of the smallest growth unit, and $k_{2}, k_{3}, k_{4}, \cdots, k_{n_{k}+1}$ (units: $\mathrm{L}^{2} \mathrm{~mol}^{-2} \mathrm{~s}^{-1}$ ) are the rate constants for aggregation reactions. Units of $k_{1}$ depend upon the values of non-elementary rate exponents $a$ and $b$. Flory's approximation $^{8}$ allows the assumption that $k_{2}=k_{3}=\ldots=k_{n_{k}+1}$.

The total concentration of the smallest growth unit in the crystalline phase (above the crystals of size greater than the size at the onset of crystal volume fraction as shown in Tables S2) is calculated as,

$$
\left[P_{1}\right]_{\text {tot }}=\sum_{h=h_{\text {crit }}}^{n} h\left[P_{h}\right]
$$


where the square brackets denote the concentration and $h_{c r i t}$ is the size at the critical crystalline volume fraction. The crystalline fraction obtained from the reaction-aggregation model is then,

$\alpha=\frac{\left[P_{1}\right]_{t o t}}{\max \left(\left[P_{1}\right]_{t o t}\right)}$

where $\max \left(\left[P_{1}\right]_{t o t}\right)$ is the concentration of the limiting reactant divided by the stoichiometric coefficient.

The remaining concentration of metal ligand and organic linker at any time are calculated through mass conservation constraint as follows,

$$
\begin{aligned}
& M=M_{0}-\left(m\left[P_{1}\right]_{t o t}\right) \\
& L=L_{0}-\left(l\left[P_{1}\right]_{t o t}\right)
\end{aligned}
$$

where, $M_{0}$ and $L_{0}$ are the initial concentrations of the metal-ligand and organic linker, respectively.

The rate of change of concentration for any $\left[P_{j}\right]$ due to aggregation with $\left[P_{i}\right]$ is given as,

$$
\left.\frac{d\left[P_{j}\right]}{d t}\right|_{i}= \begin{cases}r_{1}-k_{i}\left[P_{i}\right] \sum_{j=i}^{j-i}\left[P_{j}\right] & j=i \\ -k_{i}\left[P_{i}\right]\left[P_{j}\right] & j<2 i \\ -k_{i}\left[P_{i}\right]\left(\left[P_{j}\right]-\left[P_{j-i}\right]\right) & j+i \leq n \text { and } j \geq 2 i \\ k_{i}\left[P_{i}\right]\left[P_{j-i}\right] & j+i>n\end{cases}
$$

$\frac{d\left[P_{j}\right]}{d t}=\left.\sum_{i=1}^{n_{k}} \frac{d\left[P_{j}\right]}{d t}\right|_{i}$

where,

$$
r_{1}= \begin{cases}k_{1}[M]^{a}[L]^{b} & i=1 \\ 0 & \text { otherwise }\end{cases}
$$

The autocatalysis scheme is implemented in the rate constant for the formation of the smallest growth unit such that, 
$k_{1}= \begin{cases}k_{1} & {\left[P_{1}\right]_{\text {tot }}=0} \\ k_{1} \alpha_{s}\left[P_{1}\right]_{\text {tot }} & \text { otherwise }\end{cases}$

where, $\alpha_{s}$ is the number of available sites for the attachment of metal-ligand and organic linker to form the smallest growth unit.

The exponents $a$ and $b$, rate constants $k_{i}$, and $\alpha_{s}$ are the parameters used to fit the experimental data obtained from in-situ WAXS studies.

The higher-order growth units mentioned above can also be called clusters consisting of a certain number of monomers. To obtain theoretical grain size, we calculate the average size of the cluster at each time as follows:

$\langle i\rangle=\frac{\sum_{h=1}^{n} h\left[P_{h}\right]}{\sum_{h=1}^{n}\left[P_{h}\right]}$

The average cluster size is converted into grain size by assuming that clusters from octahedron with equal edge lengths. Hence,

$$
\frac{\langle i\rangle}{\beta}=V
$$

and,

$$
V=\frac{\sqrt{2}}{3} a_{s}^{3}
$$

where, $\beta=4.3328 \times 10^{-4} \mathrm{~A}^{-3}$ is the number of monomers per unit volume of UiO-66 lattice. $V$ is the volume of octahedron with equal edge length $a_{s}$. The edge length $a_{s}$ is the average grain size of the cluster.

$$
a_{s}=\sqrt[3]{\frac{3\langle i\rangle}{\sqrt{2} \beta}}
$$

The value $a_{s}$ is equivalent to the Scherrer width obtained from the in-situ WAXS studies. Values of the fitting parameters are given in Table S1.

\section{Effect of speciation of linker}

The experiments are performed at a constant concentration of modulator acetic acid. The modulator affects the speciation of the linker. The effect of linker speciation can be captured in the model as follows: 


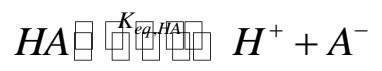

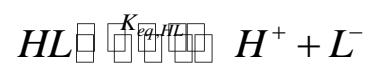

$K_{e q, H A}=\frac{\left[H^{+}\right]\left[A^{-}\right]}{[H A]_{0}-\left[A^{-}\right]}$

$K_{e q, H L}=\frac{\left[H^{+}\right]\left[L^{-}\right]}{[H L]_{0}-\left(\left[L^{-}\right]+l\left[P_{1}\right]_{t o t}\right)}$

$H^{+}=A^{-}+L^{-}$

Where, $[H A]$ is the concentration of the modulator, $[H L]$ is the concentration of non-protonated linker, $\left[H^{+}\right]$is the concentration of proton, $\left[A^{-}\right]$is the concentration of anion, $\left[L^{-}\right]$is the concentration of the protonated linker, $K_{e q, H A}$ is the equilibrium rate constant of dissociation of the modulator, and $K_{e q, H L}$ is the dissociation constant of the linker. Equation (S16) is due to the electroneutrality of the solution, $l$ is the stoichiometric coefficient of the linker in the initiation reaction, and $\left[P_{1}\right]_{t o t}$ is the total concentration of $\left[P_{1}\right]$. 


\section{Section S4: Parameter Estimation and Model Validation}

The parameters which need to be optimized are listed below:

- $\quad \alpha$ - volume of catalytic sites per unit concentration, [ $\left[\mathrm{L} \mathrm{mol}^{-1}\right]$

- $k_{1}$ - initiation rate constant, $\left[\mathrm{L}^{(a+b+1)} \mathrm{mol}^{-(a+b+1)} \mathrm{s}^{-1}\right]$

- $k_{2}$ - aggregation rate constants, $\left[\mathrm{L}^{2} \mathrm{~mol}^{-2} \mathrm{~s}^{-1}\right]$

- $n_{k}$ - maximum aggregating cluster size (MACS)

- $a$-non-elementary rate exponent for metal node concentration

- $\quad b$ - non-elementary rate exponent for ligand concentration

The procedure of error minimization:

Step 1: Non-elementary rate exponents of initiation reaction

- The initial guess for the non-elementary rate exponents is based on the crystal structure.

Step 2: Determine the datasets to be used to obtain error minimized values of rate constants

- In this study, the experimental data with $M_{0}=14.4 \mathrm{mM}$ and $L_{0}=16.3 \mathrm{mM}$ at the temperature of $25^{\circ} \mathrm{C}$ and $35^{\circ} \mathrm{C}$ is used to obtain error minimized values of rate constants

- Rate constants at $45^{\circ} \mathrm{C}$ are obtained from Arrhenius relationship

Step 3: Set $\alpha=0$, and only consider the initiation reaction to optimize the rate constant of initiation reaction $k_{1}$

- Vary the value of $k_{1}$ to minimize the error between (i) the concentration of critical size of nuclei at initial times, (ii) time of nuclei onset between theoretical results and the experimental data

Step 4: Obtain error minimized value of $\alpha$

- Vary the value of $\alpha$ to minimize the mean squared error between theoretical and experimental crystal fraction

Step 5: Obtain error minimized values of non-elementary rate exponents

- Use the experimental data with varying initial concentrations at constant temperature and vary the values of non-elementary rate exponents to minimize the mean squared error between theoretical and experimental crystal fraction

- The error surface plots are given in Figure S4-S5

Step 6: Obtain error minimized values of $n_{k}$ and $k_{2}$

- Consider the full reaction network 
- Set $n$ to a high value such that the largest crystal considered in the theoretical approach is at least two times higher than the experimentally observed steady-state grain size to capture the size distribution effectively

- Vary $n_{k}$ and $k_{2}$ to minimize the mean squared error between theoretical and experimental grain size

- The error surface plot is shown in Figure S6

Step 7: Obtain error minimized values of rate constants at $35^{\circ} \mathrm{C}$

- Set $\alpha, n_{k}$ to the error minimized values obtained from steps 4 and 6

- Vary $k_{1}$ to minimize the mean squared error between theoretical and experimental crystal fraction

- Vary $k_{2}$ to minimize the mean squared error between theoretical and experimental grain size

Step 8: Validate choice of $n_{k}$

- After obtaining error minimized values of the rate constants, validate the choice of $n_{k}$ by comparing the ratio of linker and SBU at an initial time and at the steady-state

- The ratio should fall closer to the fitted line shown in Figure $\mathbf{5 l}$ of the main manuscript

- This step needs to be done for every theoretical result used to predict crystal fraction and grain size 


\section{Section S5: Identification of Nucleation Mechanism}

Crystal growth is known to proceed using two mechanisms: (1) Classical and (2) Non-classical. The classical nucleation theory (CNT) has the following assumptions:

1. Crystal growth occurs through the addition of spherical growth units with uniform density and isotropic surface energies

2. Crystal growth occurs by the addition of one growth unit at a time

3. The size dependence of the surface energy is negligible

The non-classical nucleation theory is based upon the empirical observation that the molecules form a dense phase before the formation of a crystal. Hence it is also called a two-step nucleation process. Unlike CNT, non-classical nucleation theory is developed based on the direct observation of multiple growth units forming a crystal.

The nucleation mechanism is identified with the help of the extent of the reaction network. A reaction network is constructed using the SBUs $\left(P_{i}\right)$ as the nodes and the reactions as edges. The volumetric rate of the reaction is used as the edge weight. The extent of the reaction network using classical and non-classical nucleation mechanisms at various experimental conditions is shown in Figures S7-S12.

From the figures, it can be seen that the only non-classical nucleation mechanism allows the formation of crystals equal to or greater than the size of nuclei of 129 SBUs $(8.58 \mathrm{~nm})$. 


\section{Section S6: Justification of Flory's Approximation}

As given in the previous sections, Flory's approximation is used in the theoretical framework of MOF formation. Flory's approximation was found to be the most suitable choice based on the error minimization of the parameters and extent of the reaction network, as shown in Figures S13S17.

Flory's approximation was evident from 3 observations:

1. After obtaining the error minimized value of the rate constant $k_{2}$ as given previously, Flory's approximation was removed, and the error minimized value of $k_{2}$ was used as the initial guess. The size-dependent rate constant scheme was then implemented into the model such that reactions involving higher-order SBUs had lower rate constants. A simple reduction of $0.5 \%$ at every single size increment showed that the error increased exponentially and continued to increase further as a function of higher reduction percentages, as shown in Figure S13.

2. The reaction network extent observed using the reaction network plots shown in Figures S14 and $\mathbf{S 1 5}$ showed that an increase in the reduction percentage of the rate constant $k_{2}$ as a function of the size of the SBU significantly reduced the extent of the reaction network and did not yield the nucleation size at the onset of nucleation observed in the experiments. Only Flory's approximation yields the desired size of nuclei at the time of nucleation onset, as shown in Figure S8.

3. A very high value of $k_{2}=10^{6}$ for the smallest size of SBU with a $0.5 \%$ reduction for a single increment of the SBU size did not yield the desired steady-state grain size and only matched the dynamics at initial times as shown in Figure S16 and S17. 


\section{Section S7: Predictive Capability of the Model}

The values of parameters involved in the model are predicted for any of the other experimental conditions as follows.

Predicting rate constants using Arrhenius relationship:

$k_{i, T}=k_{i, T_{0}} \exp \left(\frac{\Delta E_{a}}{R}\left(\frac{1}{T_{0}}-\frac{1}{T}\right)\right)$

Where, $k_{i, T}$ is the rate constant at the desired temperature $T$, and $k_{i, T_{0}}$ is the rate constant at the known temperature $T_{0} . \Delta E_{a}$ is the activation barrier, and $R$ is the gas constant.

The choice of $n_{k}$ is validated with the help of the linker to SBU ratio at the initial time and at the steady state.

The values of all the other parameters are given in Table S1. 


\section{Section S8: Autocatalysis Validation}

\section{In-situ Fourier Transformed Infrared Spectroscopy (FT-IR) Study of UiO-66}

In-situ FT-IR studies were performed on a Bruker Invenio-S spectrometer in attenuated total reflectance (ATR) mode using a Pike VeeMax-III ATR module. A Ge crystal fixed on a steel base was placed on the ATR accessory. A Jackfish spectroscopic well which was treated as a microscale batch reactor, was mounted on the surface of the crystal. Initial concentrations of metal ligand and linker solutions were maintained at $14.3 \mathrm{mM}$ and $16.3 \mathrm{mM}$ at $20^{\circ} \mathrm{C}$, respectively. The spectrum at each time was recorded with a spectral resolution of $2 \mathrm{~cm}^{-1}$ at a sampling rate of $7.5 \mathrm{kHz}$. The beam aperture was set to $6 \mathrm{~mm}$, and the specular angle was set to 60 degrees. The background was subtracted with the $\mathrm{H}_{2} \mathrm{BDC}$ linker solution before introducing the ligand solution. The time of addition of the ligand solution was considered $\mathrm{t}=0 \mathrm{sec}$, and spectrum at multiple times was recorded.

\section{Potential of Mean Force Method for Autocatalysis Validation}

The attachment of a metal node (M) and an SBU with six missing linkers to (i) unit cell ( $\left.\mathrm{P}_{4}\right)$ of UiO-66 and (ii) a pristine SBU $\left(\mathrm{P}_{1}\right)$ was simulated using a semi-classical potential of mean force approach. $., 10,11$ The backward activation barrier was calculated by superimposing the energy profile of metal node attachment and the SBU attachment. Figure S20 shows the pictorial representation of the two cases.

The interaction energy as a function of distance was calculated by using the force field parameters obtained from the literature. ${ }^{12}$ The center of geometry of each configuration was used to calculate the distance between the two configurations in each energy profile. At every distance, the interaction energy was calculated by summing up the van der Waals $\left(E_{v d W}\right)$ and Coulombic contribution $\left(E_{\text {Coul }}\right)$. The functional forms used in the literature ${ }^{12}$ are given below:

$$
\begin{aligned}
E_{v d W} & =\varepsilon\left(A \exp \left[-B\left(\frac{r_{0}}{r}\right)-C\left(\frac{r}{r_{0}}\right)\right]\right) \\
E_{\text {Coul }} & =\frac{q_{1} q_{2}}{4 \pi \varepsilon_{0} r}
\end{aligned}
$$

The constants $A, B$, and $C$ in the equation (S14) are obtained from the standard MM3 force field. ${ }^{13}$ The energy profiles in each case were separated by three times (one missing linker is shared by two metal nodes) the energy required to create a missing linker defect. This value of energy was obtained from the literature. ${ }^{14}$ The intersection point of the two curves is the topmost point of the activation barrier. Figure S21 shows the pictorial representation of each energy profile labeled in Figure S20.

For Figure 3c of the main manuscript, the $\mathrm{x}$-axis was normalized to obtain reaction coordinate such that a value of zero represents the distance between the two configurations in the lattice, and the value of one represents the minimum distance where the interaction energy is zero. 
The change in the activation barrier as a function of the increasing dielectric constant of the solution medium is shown in Figure S22. The dielectric constant of the medium is incorporated in the denominator of equation (S15).

\section{Graphite Addition to Validate Autocatalysis}

The custom reactor has an approximate internal cylindrical surface of diameter $=2 \mathrm{~cm}$ and height $=4 \mathrm{~cm}$, resulting in a total surface area of $31.6 \mathrm{~cm}^{2}$

$S A=2 \pi(1 \mathrm{~cm})^{2}+2 \pi(1 \mathrm{~cm})(4 \mathrm{~cm})=31.6 \mathrm{~cm}^{2}$

Addition in $45 \mathrm{mg}$ of $20 \mu \mathrm{m}$ diameter graphite yields the following:

$S A=\frac{1 \text { particle }}{\frac{4}{3} \pi(0.001 \mathrm{~cm})^{3}} \frac{1 \mathrm{~cm}^{3}}{2.26 \mathrm{~g}} 0.045 \mathrm{~g} \frac{4 \pi(0.001 \mathrm{~cm})^{2}}{1 \text { particle }}=59.7 \mathrm{~cm}^{2}$ 


\section{Section S9: Grain Size Calculation}

To calculate the crystallite size, we employ the Scherrer equation to the [111] plane:

$$
\xi_{111}=\frac{2 \pi K}{\Delta q_{111}}
$$

Where $\Delta q_{111}$ is the full-width half maximum (FWHM) of the [111] peak, and $\mathrm{K}$ is a constant depending on grain shape, size distribution, and peak definition. For spherical crystals with cubic symmetry, as in the case of UiO- $66, \mathrm{~K} \approx 0.9394 .{ }^{15}$ It is noted that the calculated crystal coherence length is a minimum value of the crystal grain size, as defects within a crystal would reduce the coherence length while keeping the grain size constant. 


\section{Section S10: Gualtieri Model Fitting}

The Gualtieri model ${ }^{16}$ estimates the volume fraction of crystals as a probability of growing preexisting nuclei in the solution. This probability is estimated by multiplying the probability of forming nuclei in the solution with the probability of growing a nucleus in a given time interval. The intrinsic assumption of Gaussian distribution of nucleation rate along timescale yields a sigmoid shape to the Gualtieri curve that heuristically captures the autocatalysis effect. It assumes nucleation probability occurs as a Gaussian distribution centered around an induction time, $a$, with distribution, $b$ and is equivalent to the nucleation rate, $\mathrm{dN} / \mathrm{dt}$ :

$P(n)=\frac{d N}{d t}=e^{-(t-a)^{2} / 2 b^{2}}$

Where the number of nuclei at a time, $t$, is given by the integral with respect to time:

$N(t)=\frac{1}{1+e^{-(t-a) / b}}$

Each nucleus then supports the growth process, where the expression for growth is derived from the JMAK equation, where $\mathrm{kg}_{\mathrm{g}}$ is the growth rate constant, and $n$ relates to the dimension of growth:

$G(t)=\left[1-e^{-\left(k_{g} t\right)^{n}}\right]$

Multiplying the number of invisible nuclei by the growth they support yields the extent of crystallization as $\alpha$ :

$\alpha=\frac{1}{1+e^{-(t-a) / b}}\left[1-e^{-\left(k_{g} t\right)^{n}}\right]$

In this study, experimental curves were fit using the non-linear least-squares fitting tool, curvefit. Parameters were initialized by observations (i.e., $a$ could be estimated within reason upon visual inspection of the crystal volume fraction curve), other parameters were initialized by first fitting with a lower parameter Avrami equation to estimate values for $k_{g}$ and $n$. A sensitivity analysis was performed by varying parameter initialization to ensure the least-squares fit was not influenced by parameter initialization and solutions were consistent. 


\section{Section S11: Current status, limitations, and future work}

The work performed in this study unravels the following aspects of MOF growth:

1. Autocatalytic initiation mechanism: The in-situ WAXS experiments performed in this study yield insight into the formation of MOF crystals. The sigmoidal nature of the crystalline fraction curve points to the possibility that MOF growth occurs through either: (i) autocatalytic initiation mechanism or (ii) slow nucleation process. It is also possible that both events contribute to the sigmoidal nature. To further identify the cause behind the sigmoidal nature, a total of 4 validation steps are performed:

i. In-situ FT-IR experiments: The in-situ FT-IR experiments yield insight into the consumption of the reactants, unlike in-situ WAXS, where the intensity solely depends on the formation of new crystals. The rate of change of the intensity obtained from in-situ FT-IR analysis shows an initial increase followed by a decrease, indicating that the SBU formation of UiO-66 MOF proceeds through the autocatalytic mechanism. Since the reactant consumption kinetics also show an initial rate increase followed by a decrease, it points towards an autocatalytic mechanism than a non-catalytic mechanism.

ii. Semi-classical double-well approach: The reduction in the activation barrier when SBU is attaching to the lattice indicates an autocatalytic mechanism.

iii. Graphite addition to the reaction mixture: The addition of graphite to the reaction mixture does not significantly change the induction time, indicating that the activation energy required for new SBU formation on a MOF crystal is lower than the activation energy for heterogeneous nucleation. It further validates the autocatalytic mechanism

iv. The slow nucleation mechanism in the microkinetic model: As shown in equations (S2) and (S3), the model calculates the crystalline fraction by considering the concentration of crystals of size higher than the critical size. The critical size in this study is defined as the grain size at the onset of nucleation, and the exact values are given in Table S2. The optimization of the parameters (described in Section S4 and Figures S4-S6) shows that the autocatalytic mechanism is required regardless of the slow nucleation mechanism considered in the microkinetic model to validate and predict the experimental results. This observation further eliminates the possibility of slow nucleation (non-catalytic) model.

2. Chain addition (classical nucleation) and step growth (non-classical nucleation) of SBUs leading to nucleation and growth of MOFs: The microkinetic model is unbiased and yields quantitative insights into UiO-66 nucleation and growth. It relates molecular events such as chain addition, sub-critical cluster formation, and oriented attachment to the experimentally observed nucleation and growth rates.

3. Flory's approximation for the formation of new bonds between the growth units: The optimization of the variables involved in the microkinetic model shows better agreement with the experimental data when Flory's approximation is used. 
4. Termination of MOF growth based on the MACS: The MACS obtained in this study indirectly unravels the role of surface stability of UiO-66 crystals and their contributions to the growth of UiO-66 crystal.

5. Significant mechanistic insights: The microkinetic model yields more mechanistic insights than the other models published in the literature. Currently, most models aim to obtain mechanistic insights based on the fitting parameters. Some examples of such models are given in the introduction.

The limitations and future work:

1. Size-dependence of the rate constant for aggregation: Flory's approximation may not be applicable to the synthesis of other MOF crystals. However, the microkinetic model can be modified in the future to consider the size-dependent rate constant.

2. Defects in the MOF crystals during synthesis: The missing ligand or linker defects are known to occur during MOF synthesis. These defects can lead to grain boundaries that induce higher surface area and/or smaller grain size. Such a mechanism can be incorporated in the microkinetic model in the future to obtain a better match with the experimental data of MOF synthesis. 


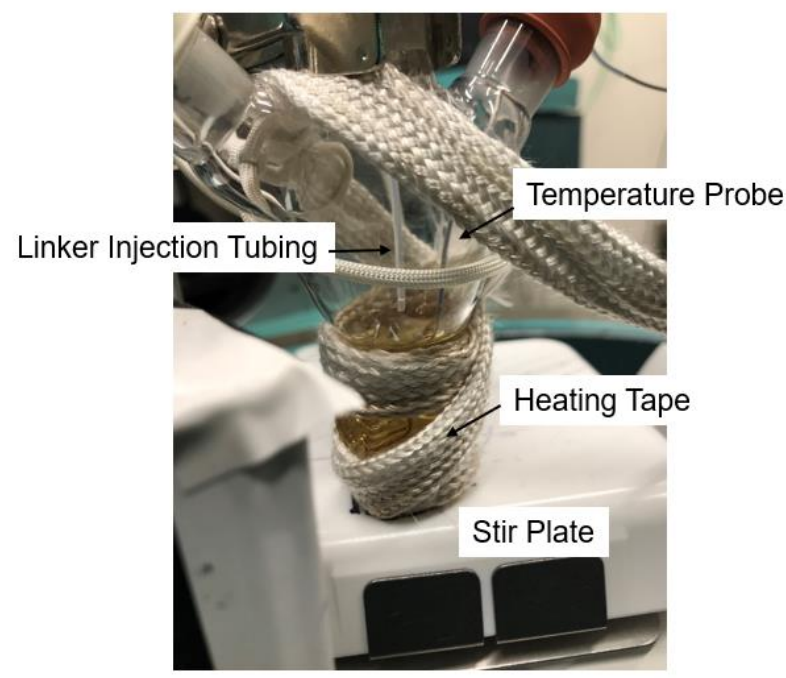

Figure S1: Experimental setup for the synthesis of UiO-66 in DMF 


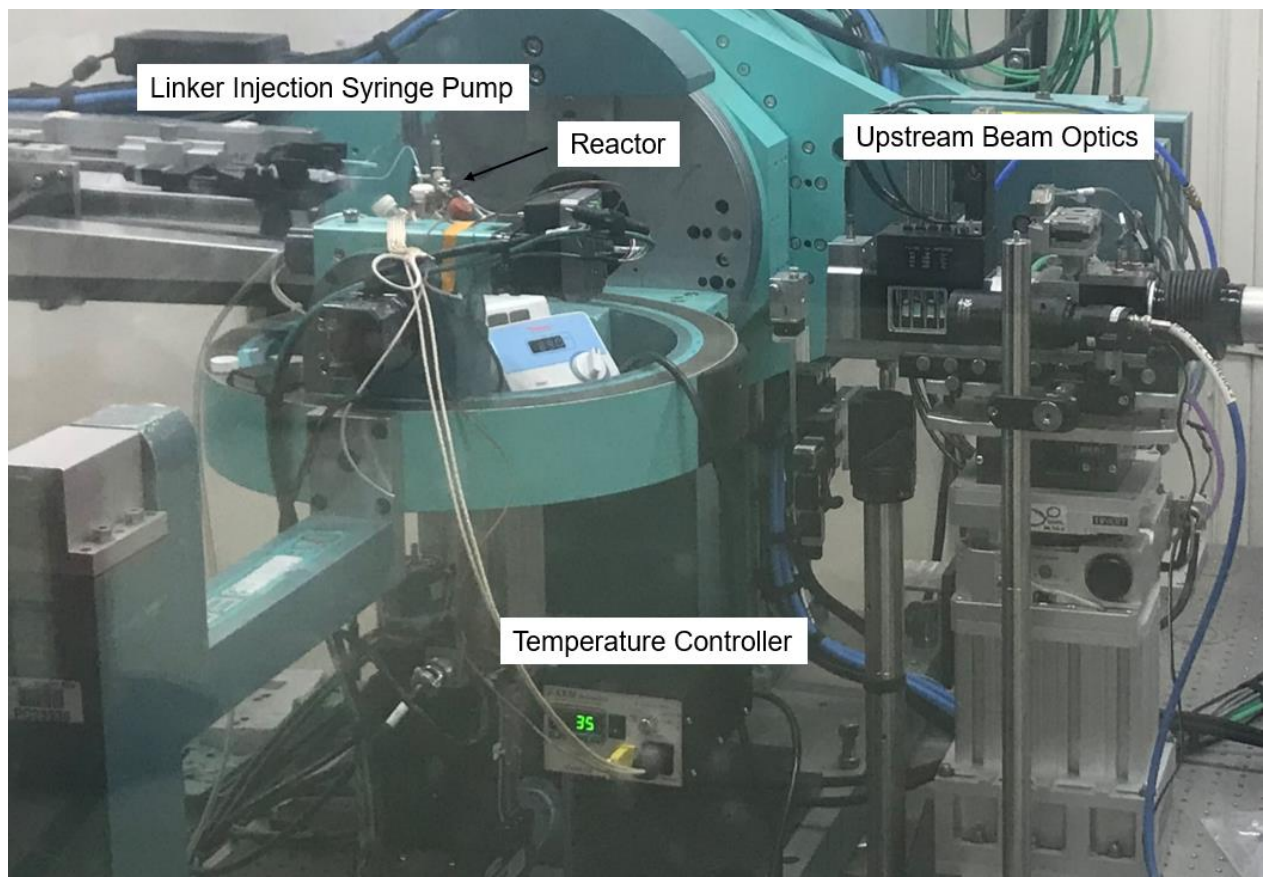

Figure S2: Beam alignment to the reactor 


\section{Features of \\ Sigmoidal Curve}

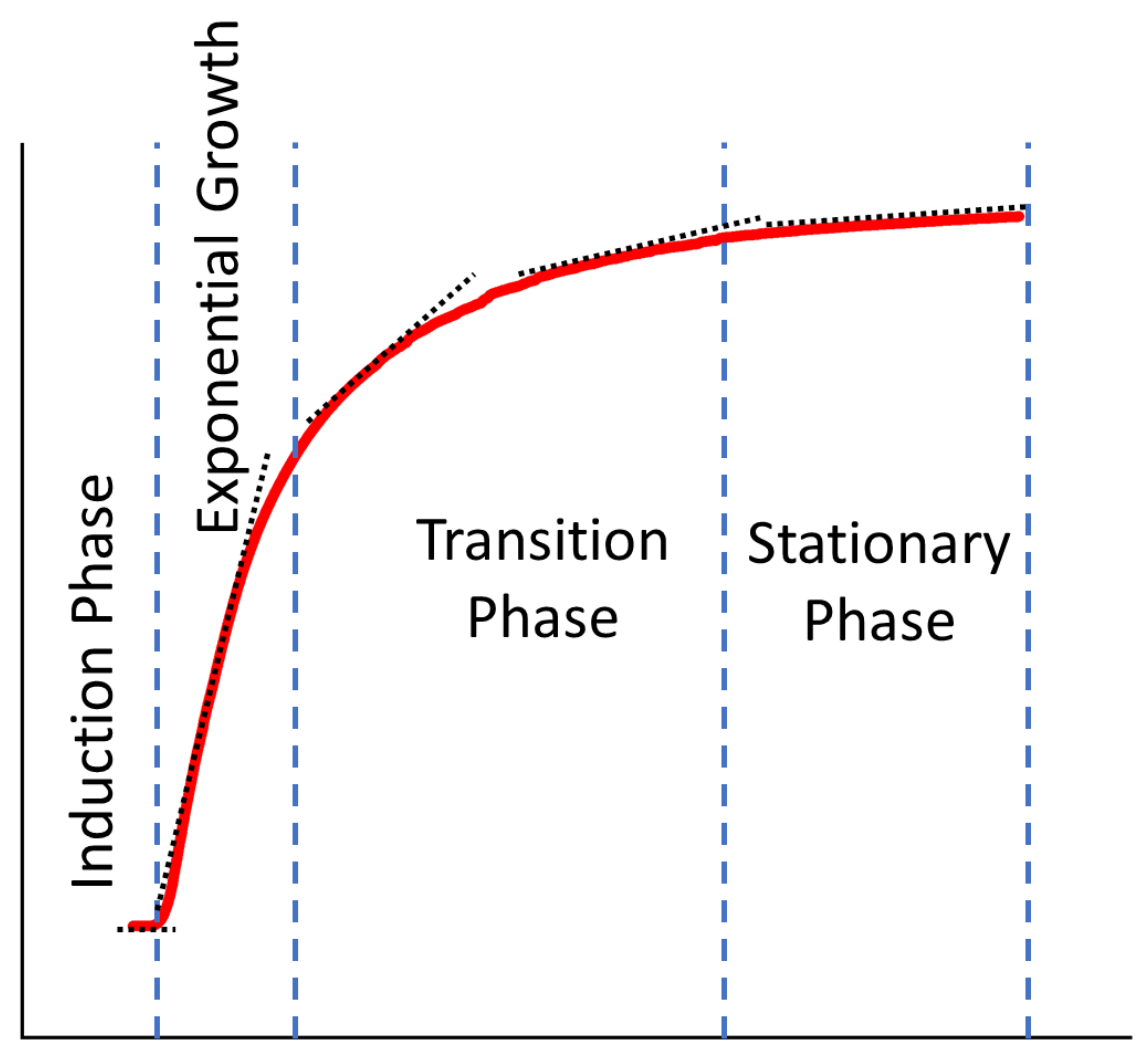

Figure S3: Features of the sigmoidal curve. The solid black lines represent the $x$ - and $y$-axis. The $\mathrm{x}$-axis represents time, and the $\mathrm{y}$-axis represents the concentration or mole fraction of the product. The dashed blue lines are used to show distinct features of the sigmoidal curve. The dotted black line represents the derivative (tangent) at various phases of the sigmoidal curve. 


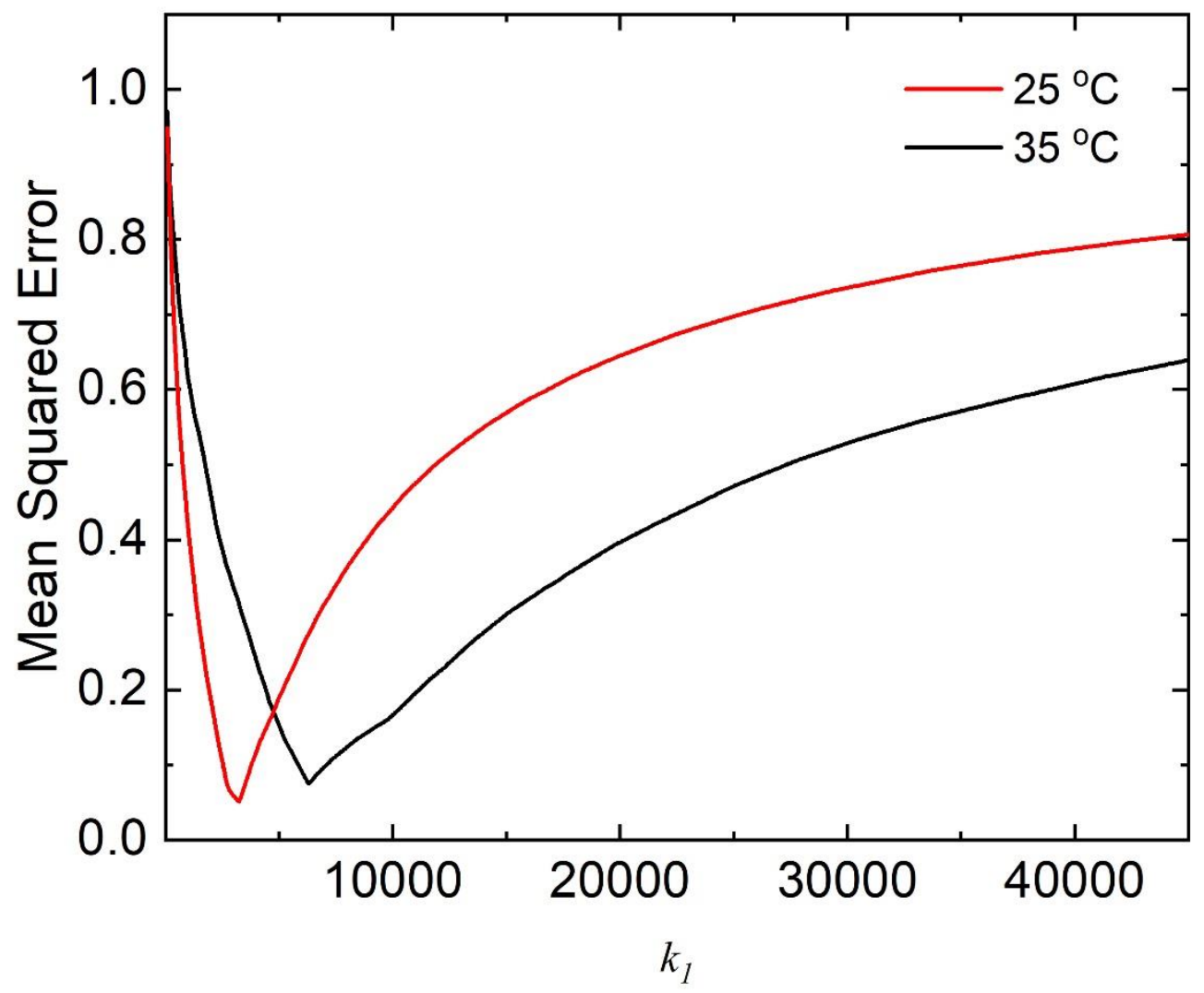

Figure S4: Error surface plot for $k_{1}$ at $M_{0}=14.4 \mathrm{mM}$ and $L_{0}=16.3 \mathrm{mM}$. 
(a) $\mathrm{Zr}=14.4 \mathrm{mM}, \mathrm{H} 2 \mathrm{BDC}=16.3 \mathrm{mM}, 25 \mathrm{C}$

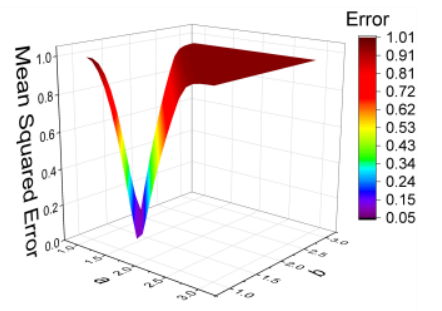

(b) $\mathrm{Zr}=7.2 \mathrm{mM}, \mathrm{H} 2 \mathrm{BDC}=16.3 \mathrm{mM}, 25 \mathrm{C}$

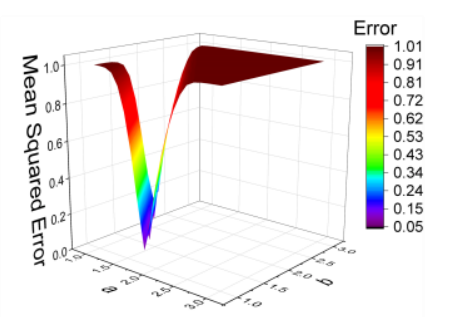

(c) $\mathrm{Zr}=14.4 \mathrm{mM}, \mathrm{H} 2 \mathrm{BDC}=8.15 \mathrm{mM}, 25 \mathrm{C}$

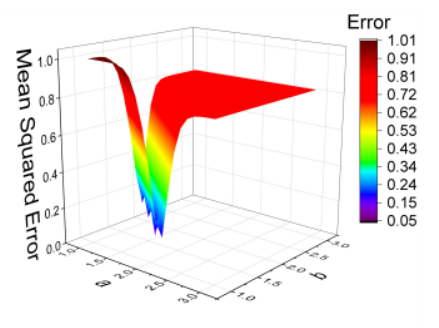

Figure S5: Optimization of non-elementary rate exponents of the initiation reaction. 


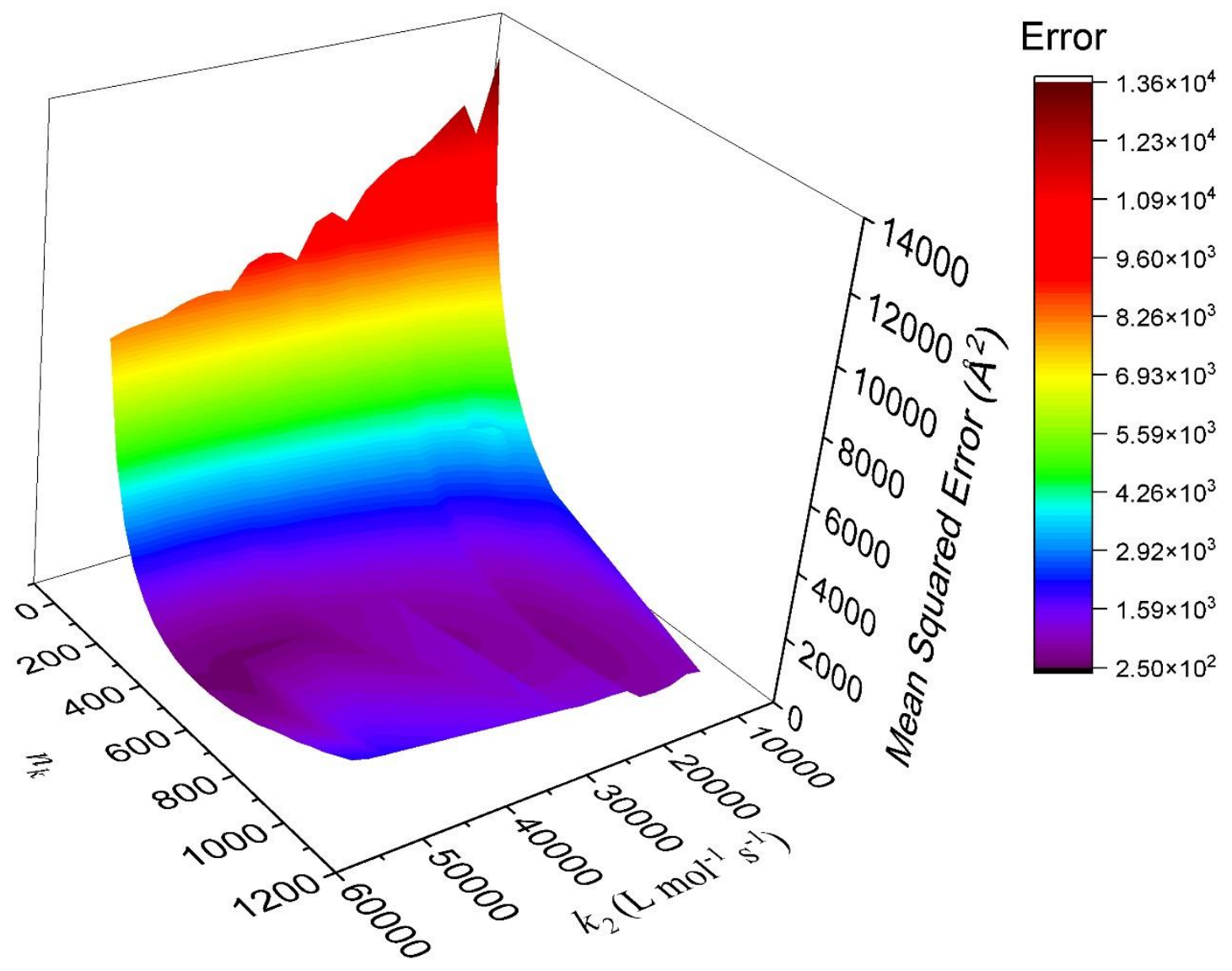

Figure S6: Error surface plot for $n_{k}$ and $k_{2}$ at $M_{0}=14.4 m M, L_{0}=16.3 m M$ and $\mathrm{T}=25^{\circ} \mathrm{C}$ 


\section{4 $\mathrm{mM} \mathrm{Zr}, 16.3 \mathrm{mM} \mathrm{H}_{2} \mathrm{BDC}, 25^{\circ} \mathrm{C}$ (Classical)}

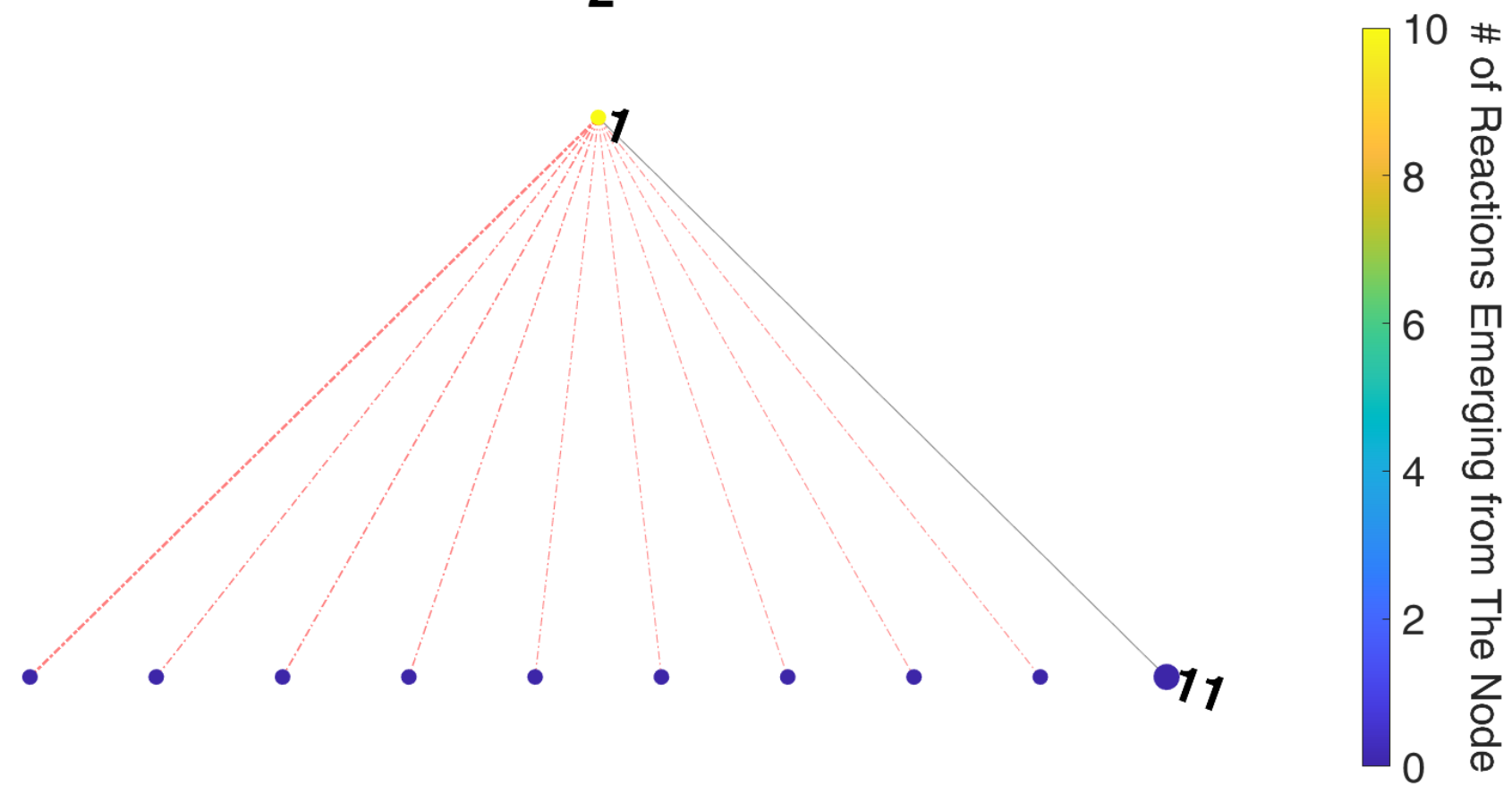

Figure S7: The extent of the reaction network at the time of nucleation onset. The reaction network begins at $\mathrm{P}_{1}$ (labeled as 1 ) and extends to the highest possible SBU size denoted by the larger node when only a classical nucleation mechanism is considered. The title represents the initial concentrations of metal node and organic linker and temperature. The onset of nucleation for the given experimental conditions from in-situ WAXS is around 45 seconds. The edge thickness is relative to the highest volumetric rate theoretically observed in all of the experimental conditions. The solid black line denotes the dominant pathway to obtain the largest size of the SBU. 


\section{4 mM Zr, $16.3 \mathrm{mM} \mathrm{H}_{2} \mathrm{BDC}, 25^{\circ} \mathrm{C}$ (Non-Classical)}

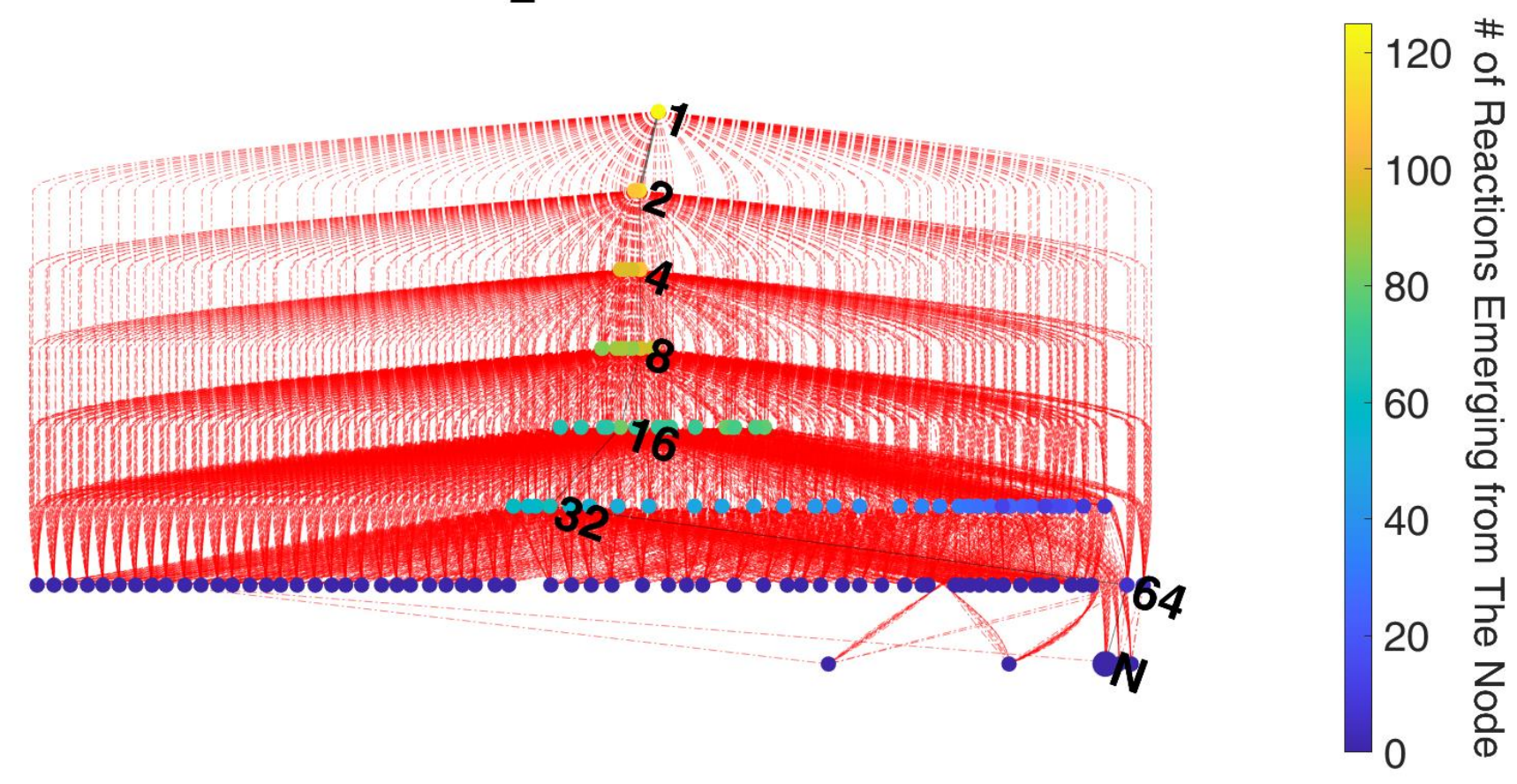

Figure S8: The extent of the reaction network at the time of nucleation onset. The reaction network begins at $\mathrm{P}_{1}$ (labeled as 1 ) and extends to the critical nuclei size denoted by the larger node $(\mathrm{N}=129)$ when a non-classical nucleation mechanism is considered. The title represents the initial concentrations of metal node and organic linker and temperature. The onset of nucleation for the given experimental conditions from in-situ WAXS is around 45 seconds. The edge thickness is relative to the highest volumetric rate theoretically observed in all of the experimental conditions. The solid black line denotes the dominant pathway to obtain the critical size of the nuclei. 


\section{4 $\mathrm{mM} \mathrm{Zr}, 16.3 \mathrm{mM} \mathrm{H}_{2} \mathrm{BDC}, 45^{\circ} \mathrm{C}$ (Classical)}

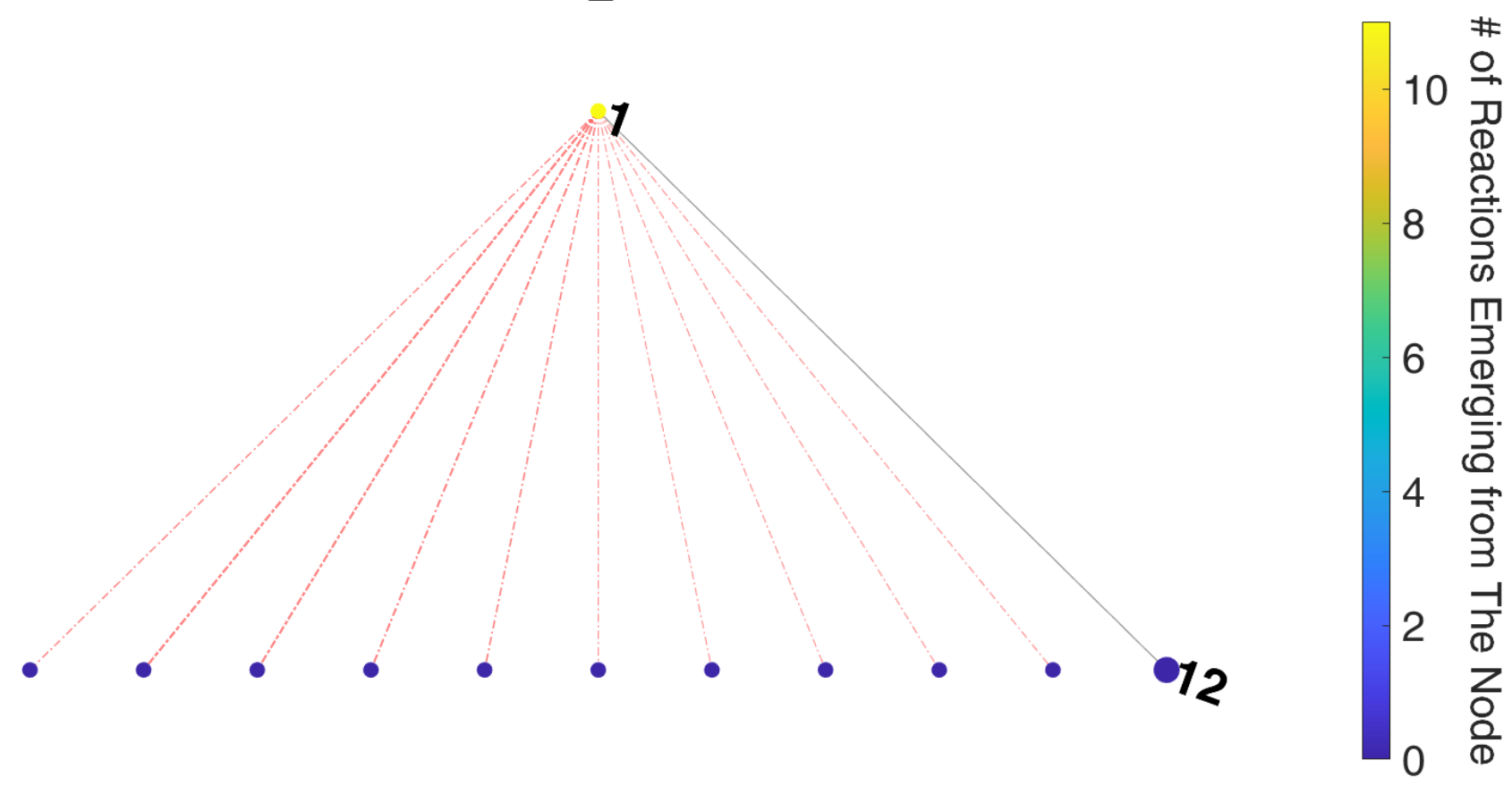

Figure S9: The extent of the reaction network at the time of nucleation onset. The reaction network begins at $\mathrm{P}_{1}$ (labeled as 1 ) and extends to the highest possible SBU size denoted by the larger node when only a classical nucleation mechanism is considered. The title represents the initial concentrations of metal node and organic linker and temperature. The onset of nucleation for the given experimental conditions from in-situ WAXS is around 6 seconds. The edge thickness is relative to the highest volumetric rate theoretically observed in all of the experimental conditions. The solid black line denotes the dominant pathway to obtain the largest size of the SBU. 


\section{4 $\mathrm{mM} \mathrm{Zr}, 16.3 \mathrm{mM} \mathrm{H} \mathrm{HDC} \mathrm{BD}{ }^{\circ} \mathrm{C}$ (Non-Classical)}

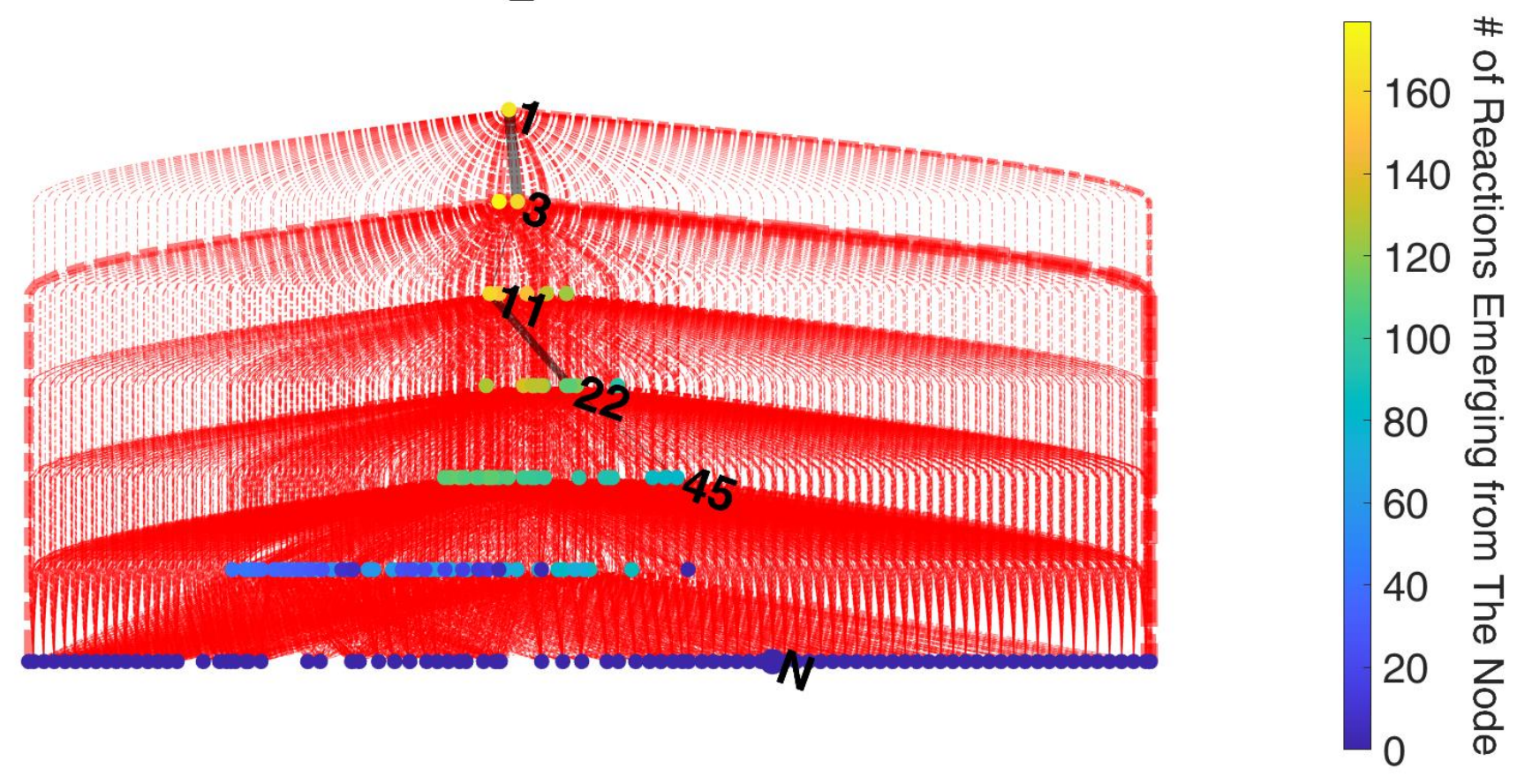

Figure S10: The extent of the reaction network at the time of nucleation onset. The reaction network begins at $\mathrm{P}_{1}($ labeled as 1$)$ and extends to the critical nuclei size denoted by the larger node $(\mathrm{N}=129)$ when a non-classical nucleation mechanism is considered. The title represents the initial concentrations of metal node and organic linker and temperature. The onset of nucleation for the given experimental conditions from in-situ WAXS is around 6 seconds. The edge thickness is relative to the highest volumetric rate theoretically observed in all of the experimental conditions. The solid black line denotes the dominant pathway to obtain the critical size of the nuclei. 


\section{2 mM Zr, $16.3 \mathrm{mM} \mathrm{H}_{2} \mathrm{BDC}, 25^{\circ} \mathrm{C}$ (Classical)}

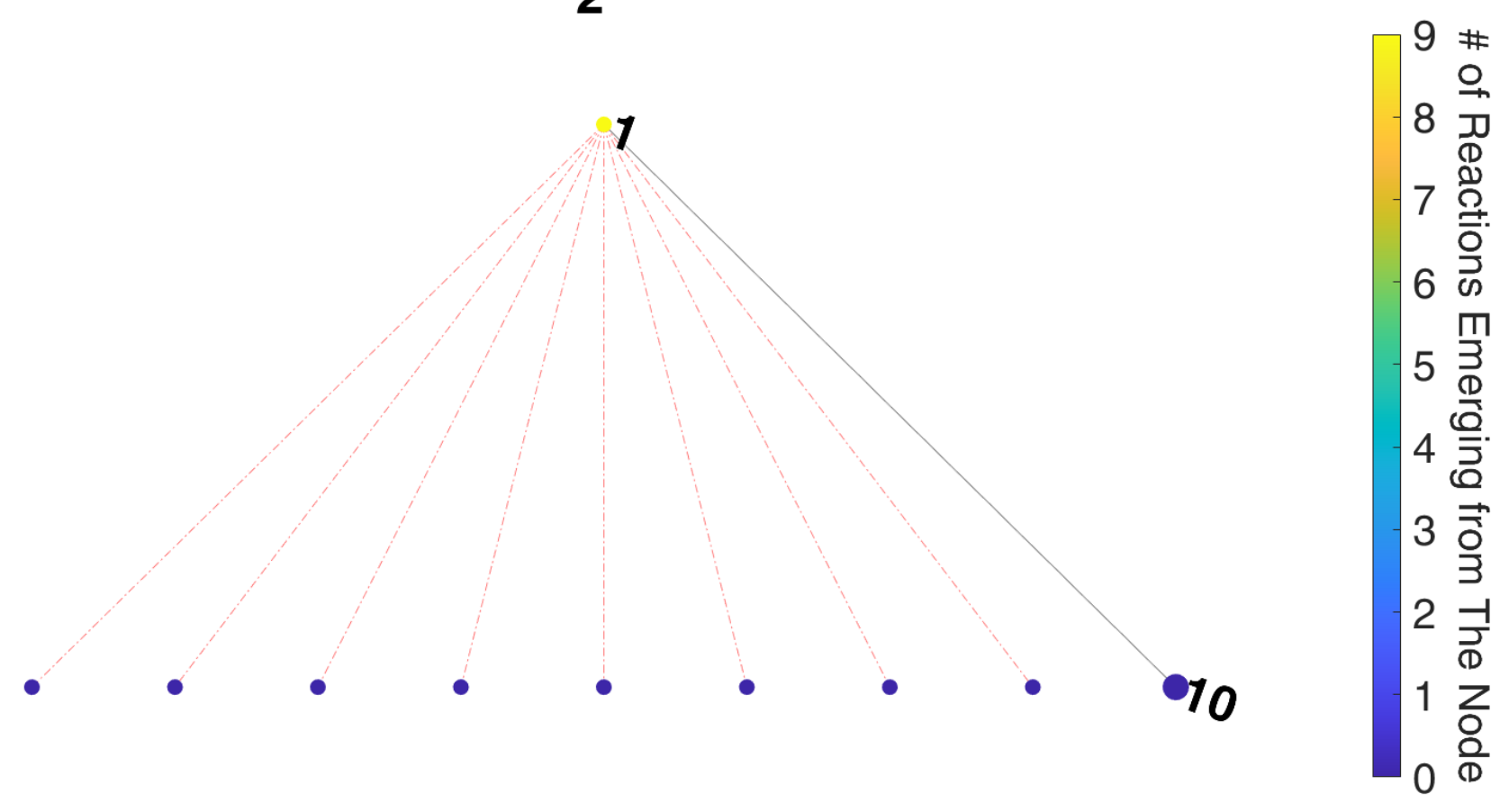

Figure S11: The extent of the reaction network at the time of nucleation onset. The reaction network begins at $\mathrm{P}_{1}$ (labeled as 1 ) and extends to the highest possible SBU size denoted by the larger node when only a classical nucleation mechanism is considered. The title represents the initial concentrations of metal node and organic linker and temperature. The onset of nucleation for the given experimental conditions from in-situ WAXS is around 115 seconds. The edge thickness is relative to the highest volumetric rate theoretically observed in all of the experimental conditions. The solid black line denotes the dominant pathway to obtain the largest size of the SBU. 


\section{$7.2 \mathrm{mM} \mathrm{Zr}, 16.3 \mathrm{mM} \mathrm{H}_{2} \mathrm{BDC}, 25^{\circ} \mathrm{C}$ (Non-Classical)}
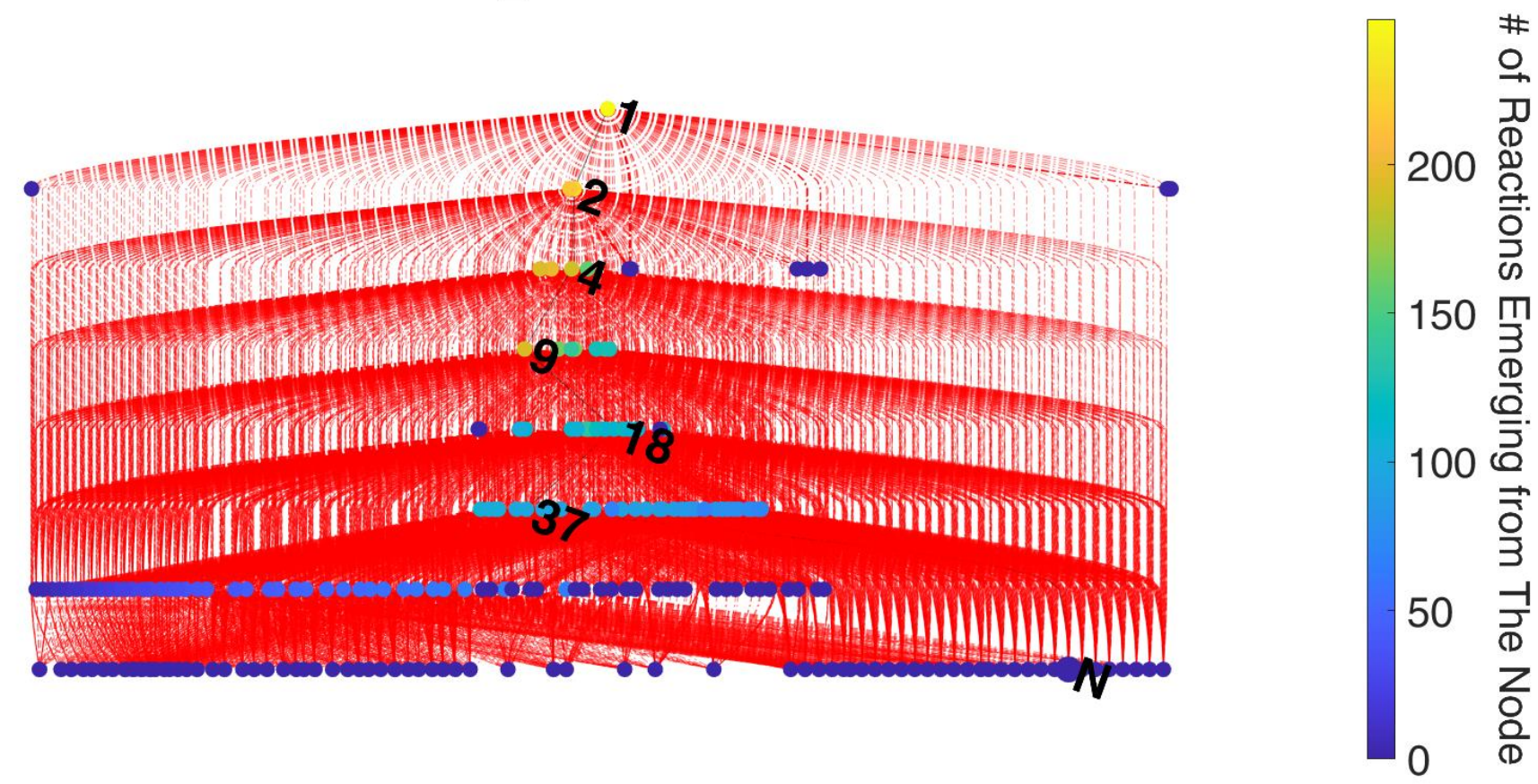

Figure S12: The extent of the reaction network at the time of nucleation onset. The reaction network begins at $\mathrm{P}_{1}$ (labeled as 1 ) and extends to the critical nuclei size denoted by the larger node $(\mathrm{N}=129)$ when a non-classical nucleation mechanism is considered. The title represents the initial concentrations of metal node and organic linker and temperature. The onset of nucleation for the given experimental conditions from in-situ WAXS is around 115 seconds. The edge thickness is relative to the highest volumetric rate theoretically observed in all of the experimental conditions. The solid black line denotes the dominant pathway to obtain the critical size of the nuclei. 
Error in Grain Size

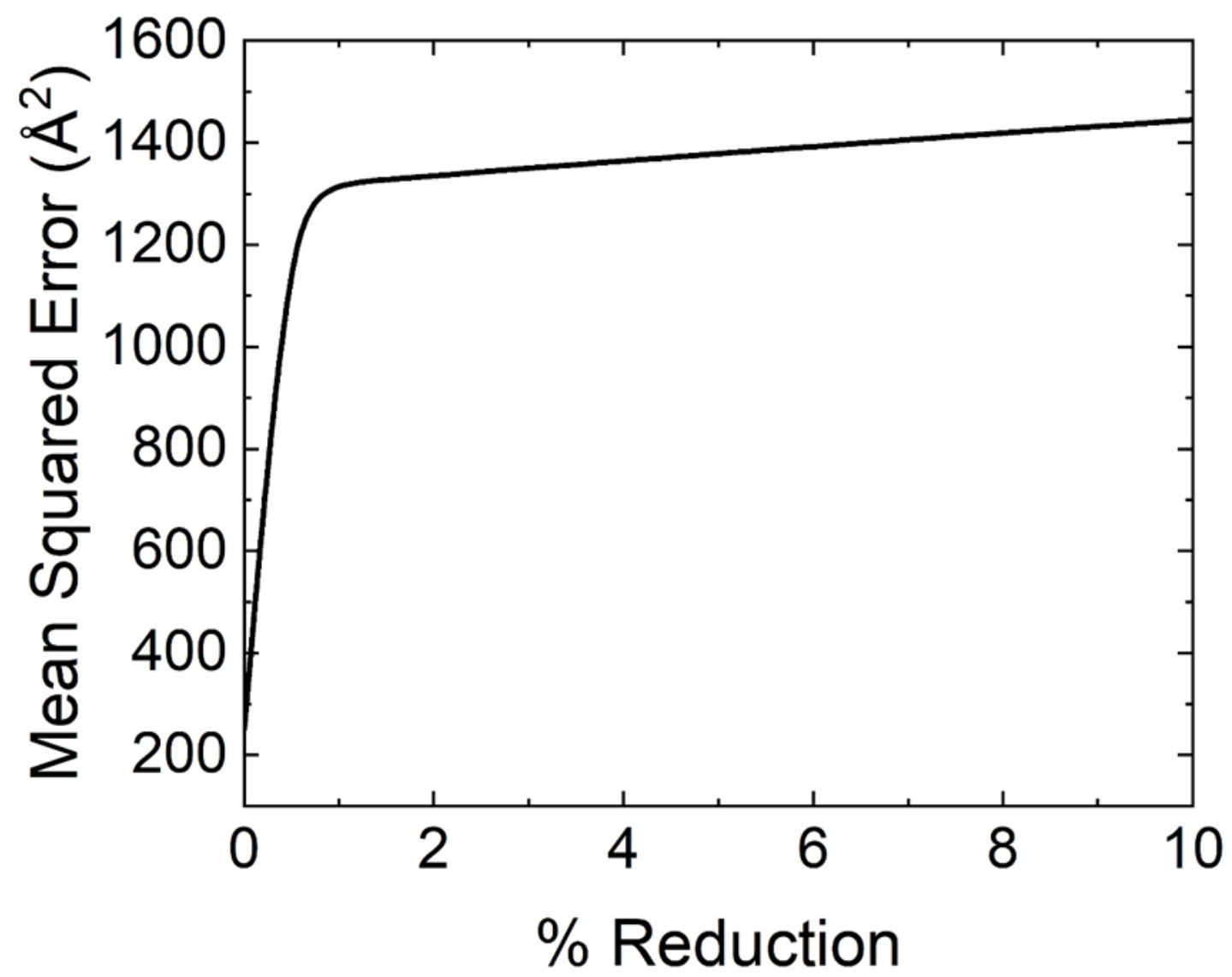

Figure S13: Error in grain size when size-dependent rate constant of aggregation $\left(k_{2}\right)$ is considered. The $\mathrm{x}$-axis indicates the percent reduction at every single increment of SBU size. The value of zero represents Flory's approximation with the rate constant value equal to the optimized value as given in Table S1. Values higher than zero represent the size-dependent rate constant of aggregation. The error is calculated as the time-averaged squared error in grain size between theoretical and experimental grain size. The experimental condition considered in this calculation has an initial concentration of metal-ligand and linker as $14.4 \mathrm{mM}$ and $16.3 \mathrm{mM}$, respectively, at $25{ }^{\circ} \mathrm{C}$. 


\section{$0.5 \%$ Reduction}

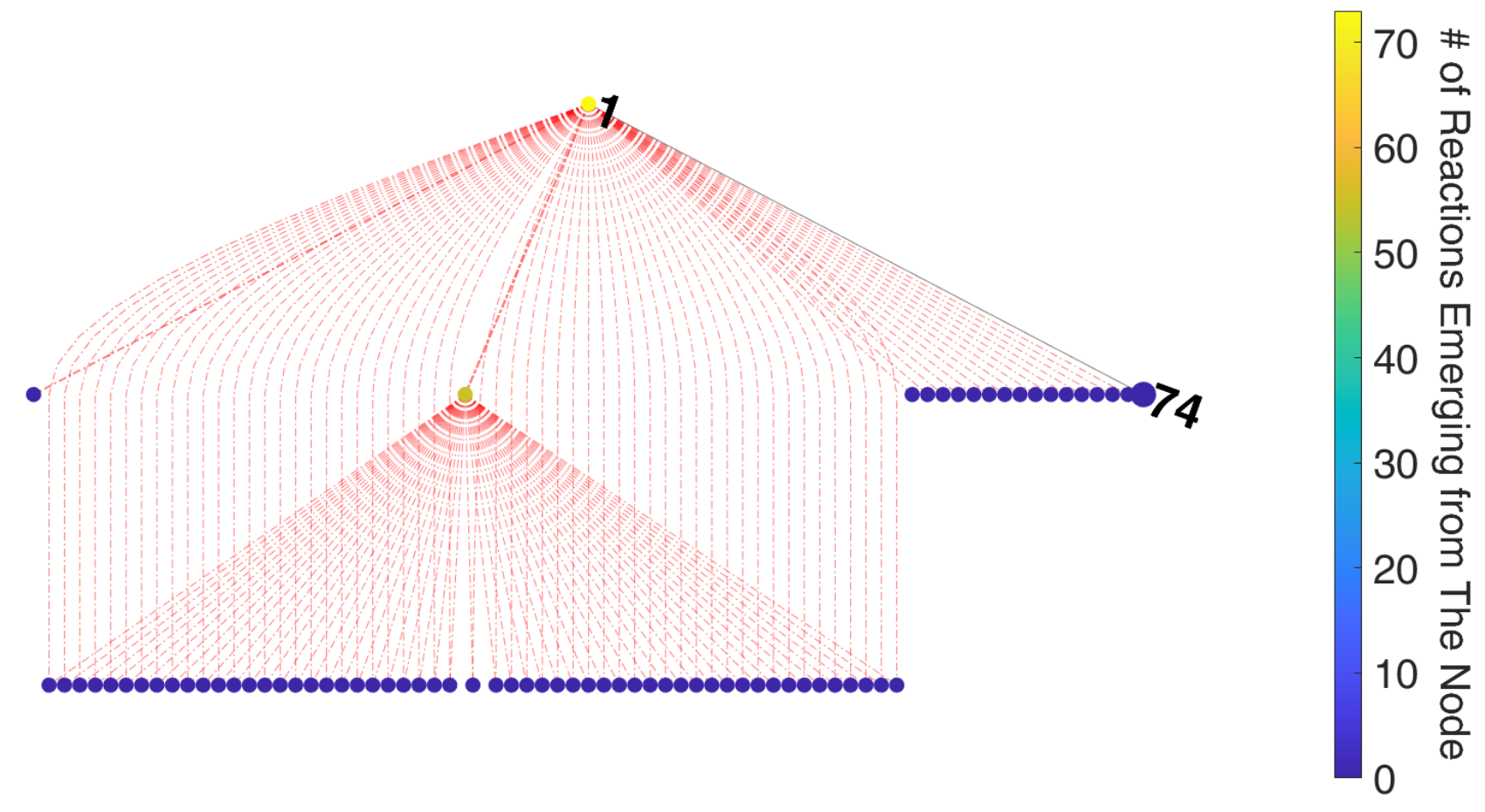

Figure S14: The extent of the reaction network at the time of nucleation onset. The reaction network begins at $\mathrm{P}_{1}$ (labeled as 1 ) and extends to the highest possible SBU size denoted by the larger node when the size-dependent rate constant of aggregation is considered. The rate constant was reduced by $0.5 \%$ at every single size increment. The experimental condition considered in this calculation has the initial concentrations of metal node and organic linker, as $14.4 \mathrm{mM}$ and $16.3 \mathrm{mM}$, respectively, at $25^{\circ} \mathrm{C}$. The onset of nucleation for the given experimental conditions from in-situ WAXS is around 45 seconds. The edge thickness is relative to the highest volumetric rate theoretically observed in all of the experimental conditions. The solid black line denotes the dominant pathway to obtain the largest size of the SBU. 


\section{$5 \%$ Reduction}

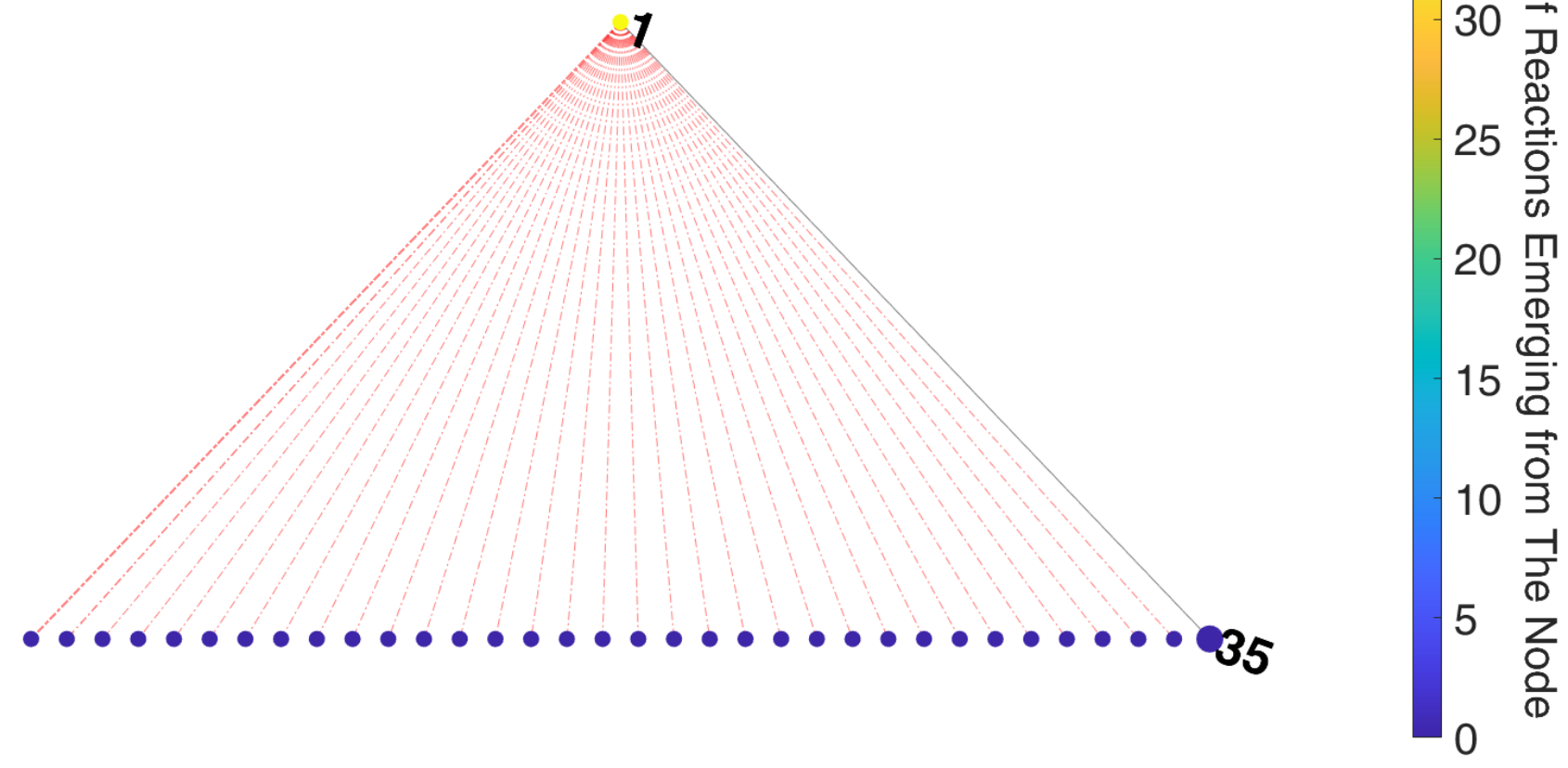

Figure S15: The extent of the reaction network at the time of nucleation onset. The reaction network begins at $\mathrm{P}_{1}$ (labeled as 1 ) and extends to the highest possible SBU size denoted by the larger node when size-dependent rate constant of aggregation is considered. The rate constant was reduced by $5 \%$ at every single size increment. The experimental condition considered in this calculation has the initial concentrations of metal node and organic linker, as $14.4 \mathrm{mM}$ and $16.3 \mathrm{mM}$, respectively, at $25^{\circ} \mathrm{C}$. The onset of nucleation for the given experimental conditions from in-situ WAXS is around 45 seconds. The edge thickness is relative to the highest volumetric rate theoretically observed in all of the experimental conditions. The solid black line denotes the dominant pathway to obtain the largest size of the SBU. 


\section{$k_{2,1}=10^{6}$ with $0.5 \%$ Reduction}

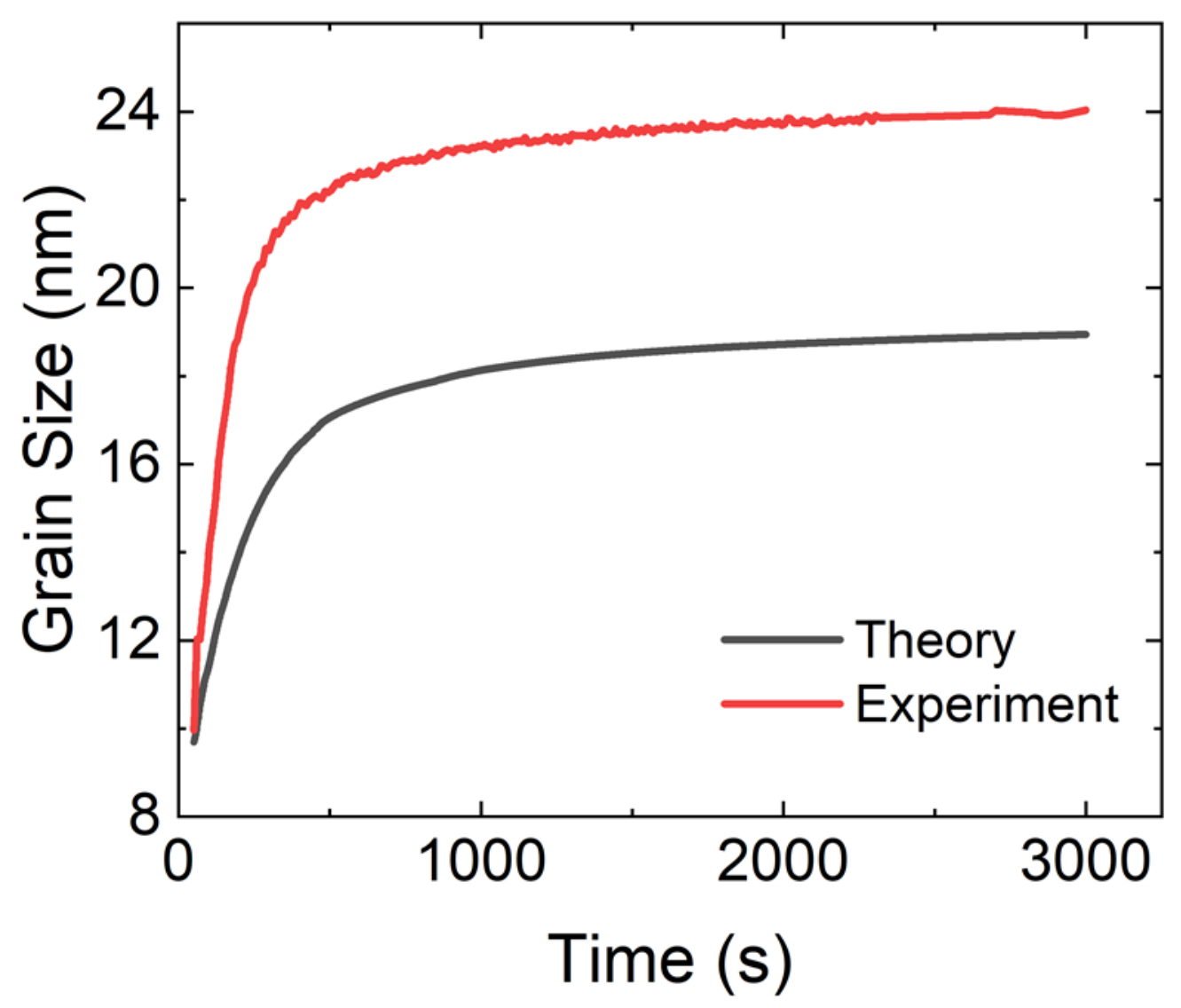

Figure S16: Theoretical and experimental grain size when the size-dependent rate constant of aggregation is considered. The rate constant $\left(k_{2,1}\right)$ for the reactions which involve aggregation of the smallest $\mathrm{SBU}\left(\mathrm{P}_{1}\right)$ has the value of $10^{6}$. The rate constant is then reduced by $0.5 \%$ at every single size increment of SBU. 


\section{Size Distribution $k_{2,1}=10^{6}$}

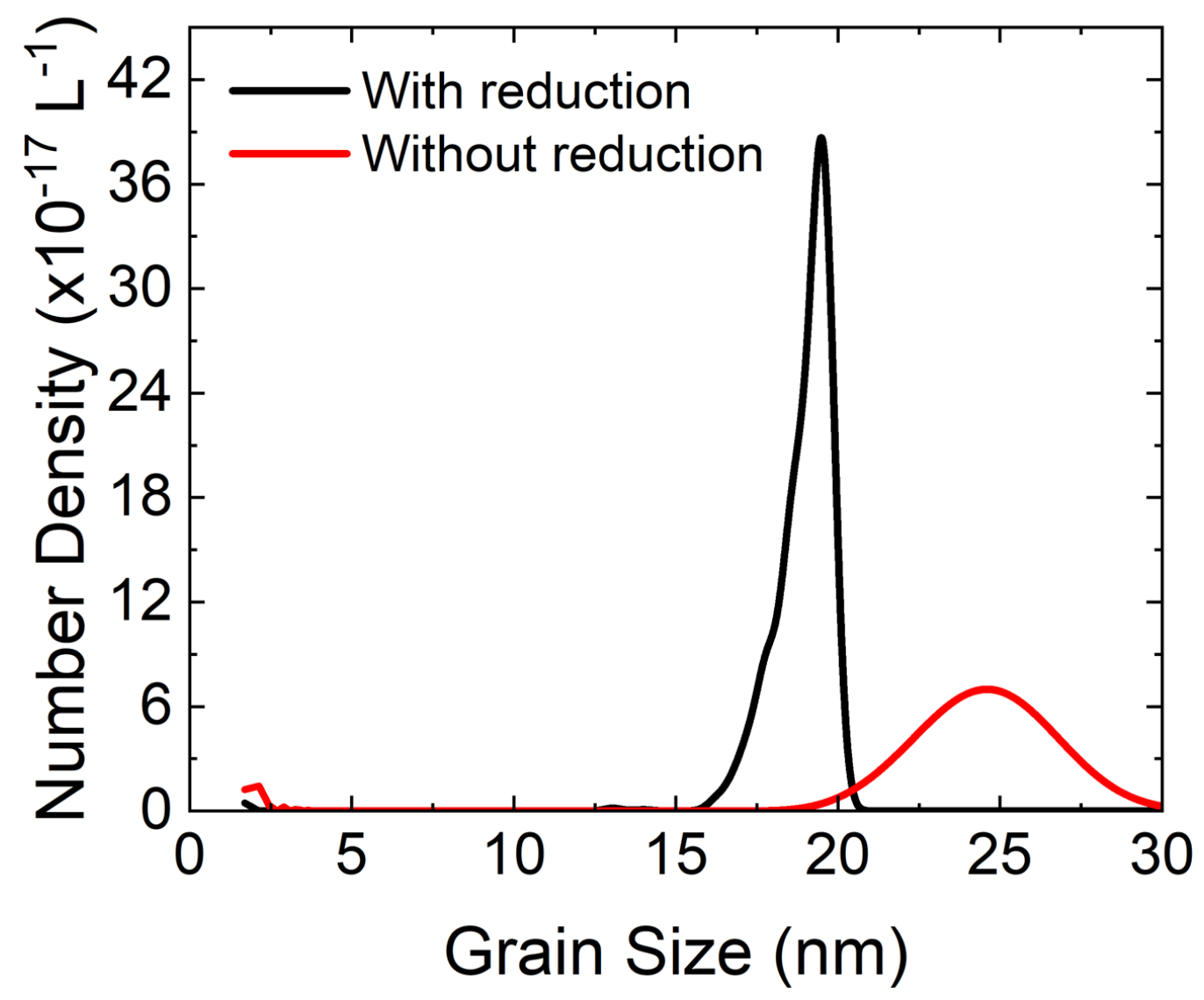

Figure S17: Theoretical steady-state size distribution of crystals with and without (Flory's approximation) reduction. For the size-dependent rate constant case, the rate constant $\left(k_{2,1}\right)$ for the reactions which involve aggregation of the smallest $\operatorname{SBU}\left(\mathrm{P}_{1}\right)$ has the value of $10^{6}$. The rate constant is then reduced by $0.5 \%$ at every single size increment of SBU. 
(a) Nucleation Profiles (Temperature)

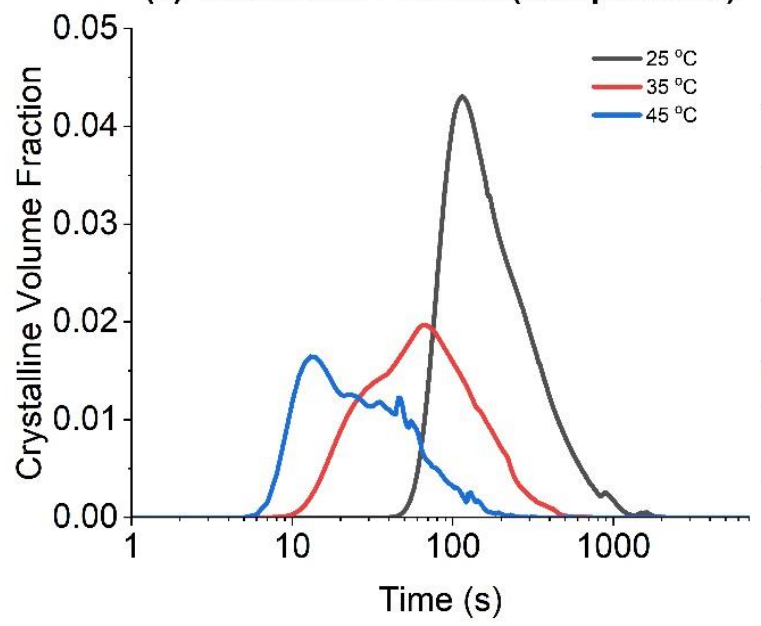

(b) Nucleation Profiles (Concentration)

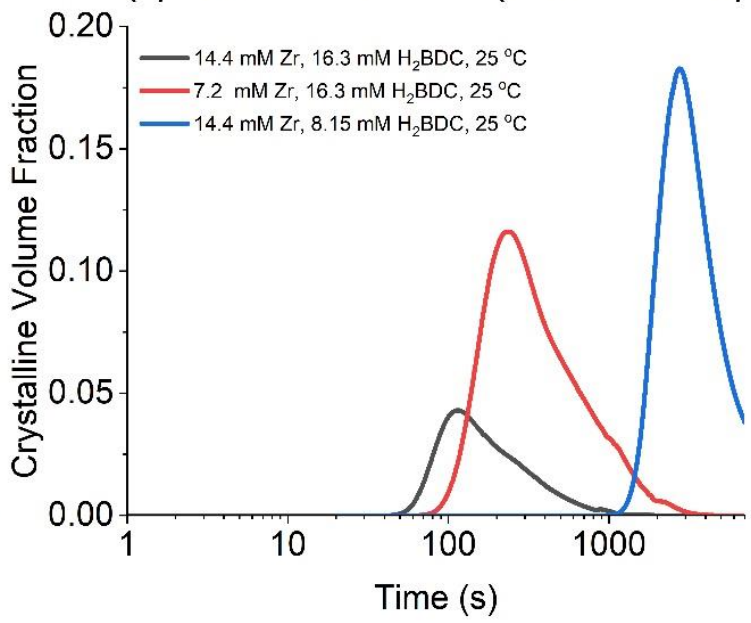

Figure S18: Contribution of nuclei to crystalline volume fraction as a function of (a) temperature and (b) concentration 


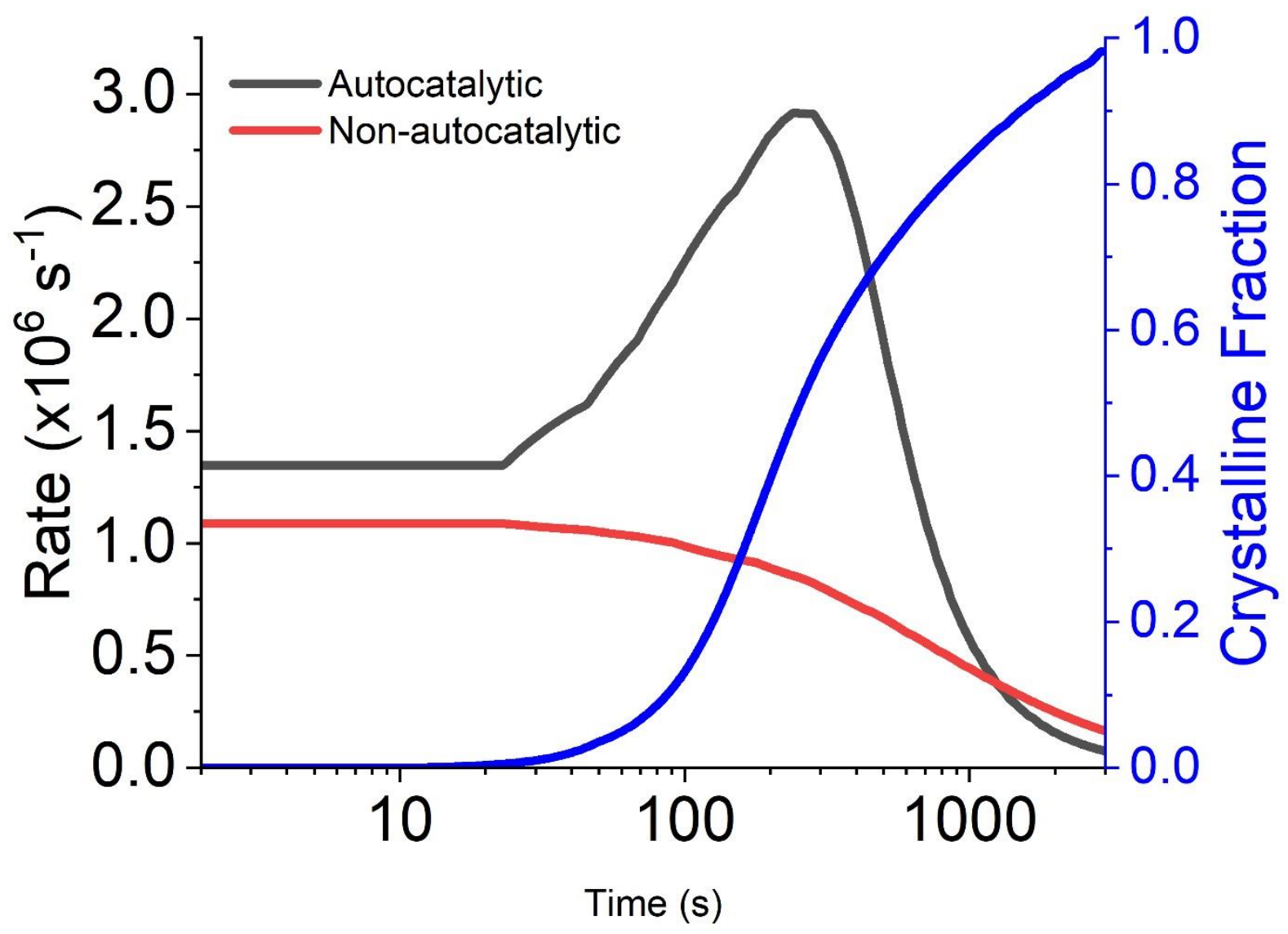

Figure S19: Theoretical molar rate with and without autocatalytic scheme for $M_{0}=14.4 \mathrm{mM}$, $L_{0}=16.3 \mathrm{mM}$ and $T=25^{\circ} \mathrm{C}$. The blue line indicates crystalline fraction. 


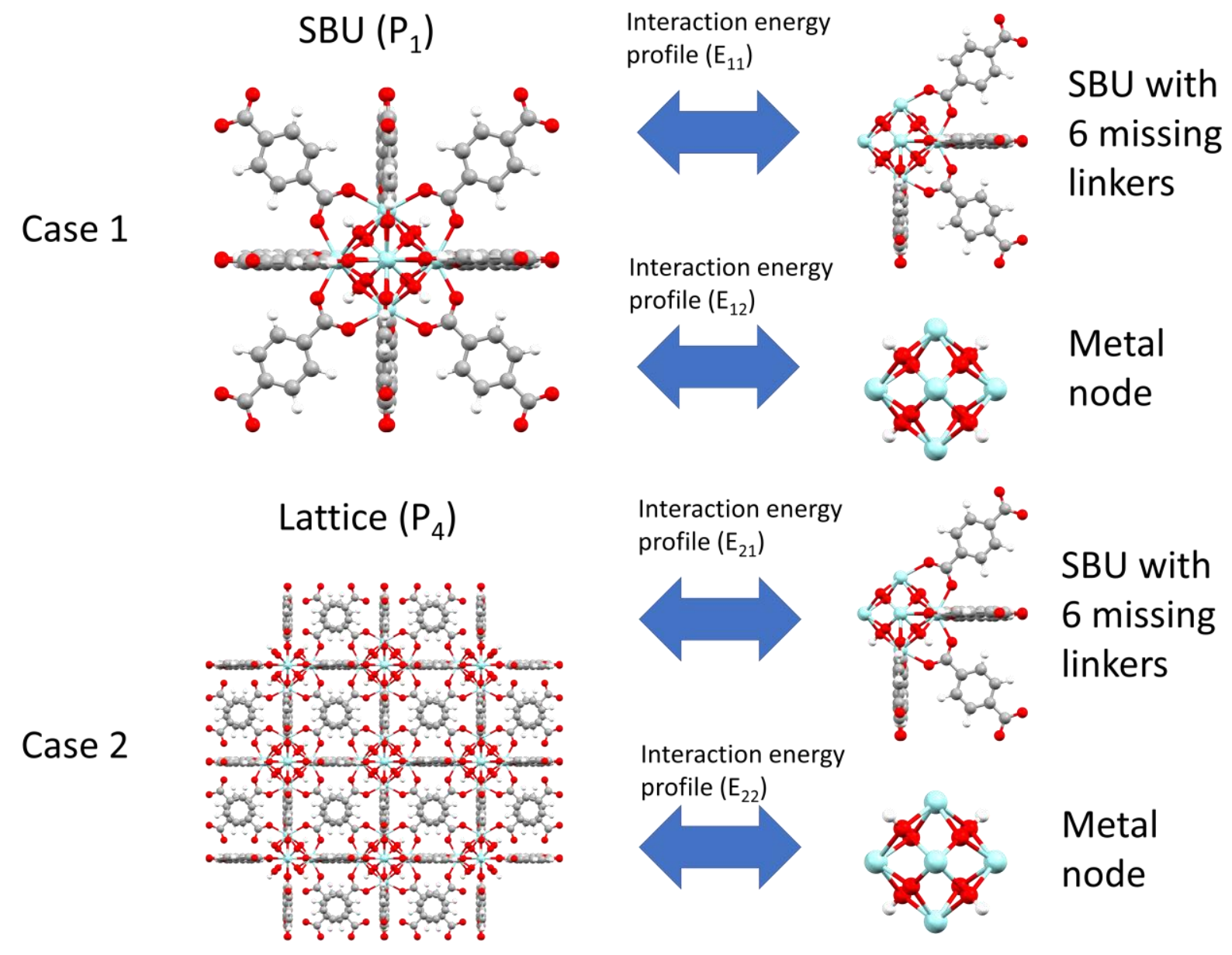

Figure S20: The pictorial representation of the two cases for which attachment energy is calculated. Case 1 shows the attachment of a defective SBU with six missing linkers and a metal node to a pristine $\mathrm{SBU}\left(\mathrm{P}_{1}\right)$, and case 2 shows the attachment of a defective SBU with six missing linkers and a metal node to a full lattice $\left(\mathrm{P}_{4}\right)$. The energy profiles are labeled as $\mathrm{E}_{\mathrm{ij}}$, where the subscript $\mathrm{i}$ refers to the case number and subscript $\mathrm{j}=1$ represents defective $\mathrm{SBU}$, or $\mathrm{j}=2$ represents a metal node. The color-coding of the atoms on the molecular structure is as follows: gray - carbon $(\mathrm{C})$, red - oxygen $(\mathrm{O})$, white - hydrogen $(\mathrm{H})$, and cyan - Zirconium $(\mathrm{Zr})$. 
(a)

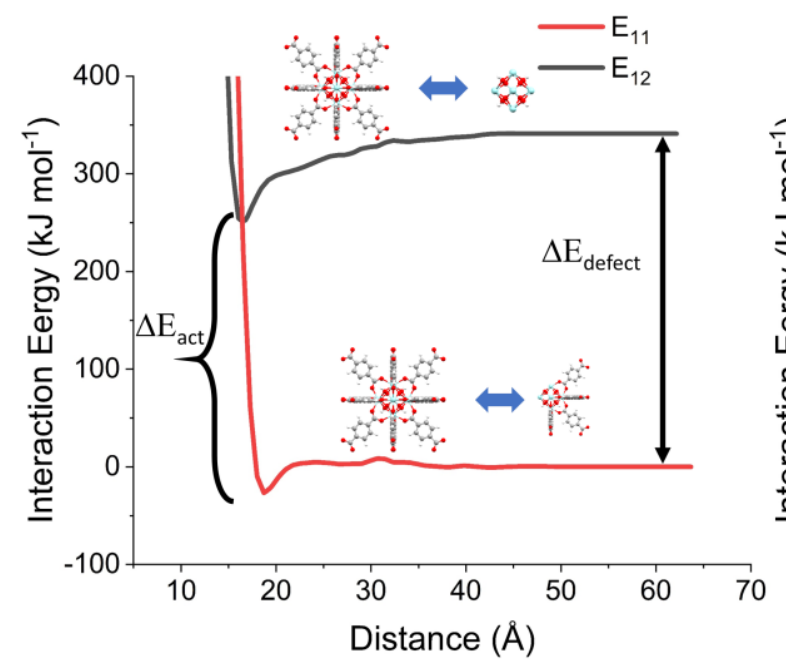

(b)

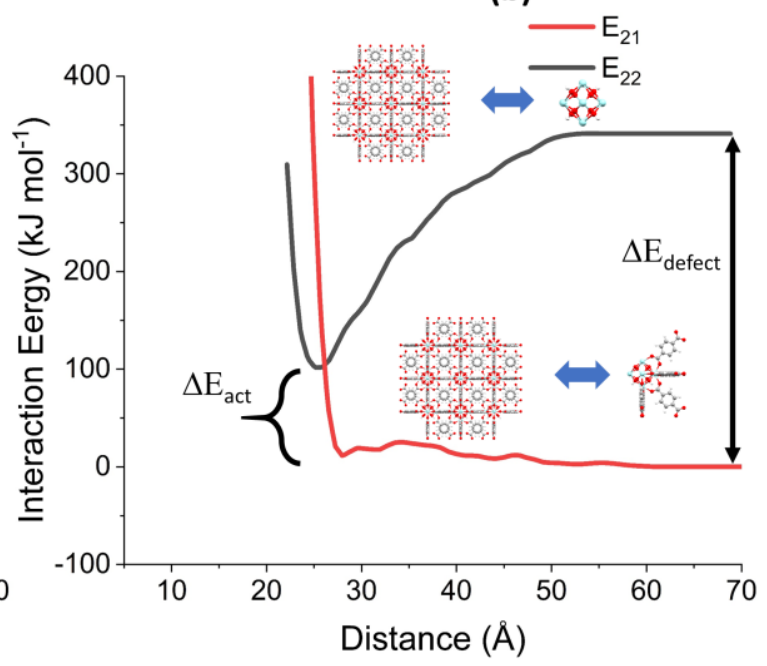

Figure S21: Interaction energy profiles. (a) Interaction energy profile of defective SBU (red curve) and metal node (black curve) attaching to pristine SBU. (b) Interaction energy profile of defective SBU (red curve) and metal node (black curve) attaching to a full lattice. The two energy profiles in (a) and (b) are separated by the energy required to cause three missing linker defects. Legends represent the energy profiles as depicted in figure S5. The intersection point of the two curves is the topmost point of the activation barrier and the minima of the bottom (red) curve serves as the starting point of the activation energy profile shown in figure $2 \mathrm{f}$ of the main manuscript. 

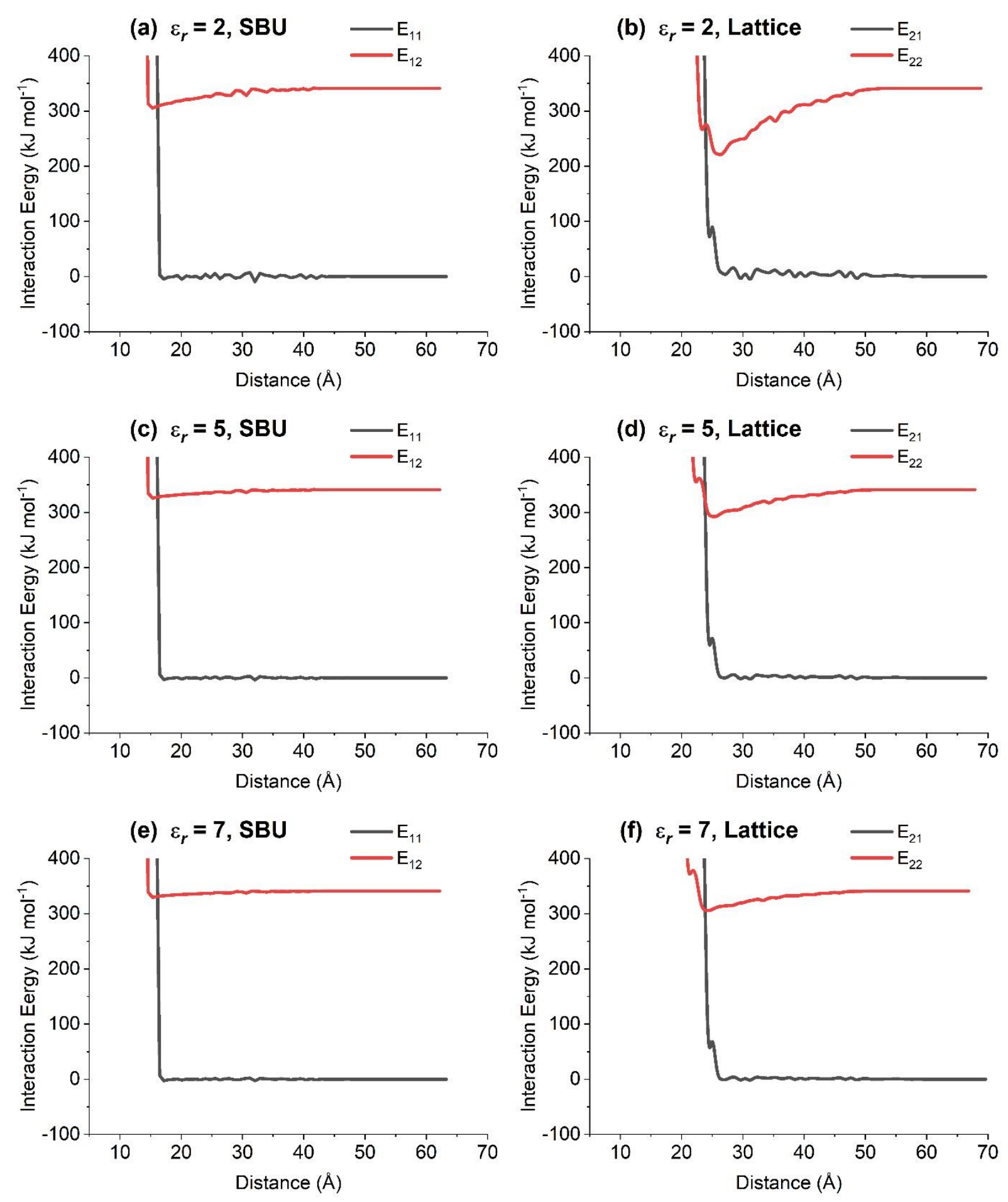

Figure S22: Activation barrier for attachment of the defective SBU to a pristine SBU (left panels) and a lattice (right panels) at various values of dielectric constants given in the title of each panel. 


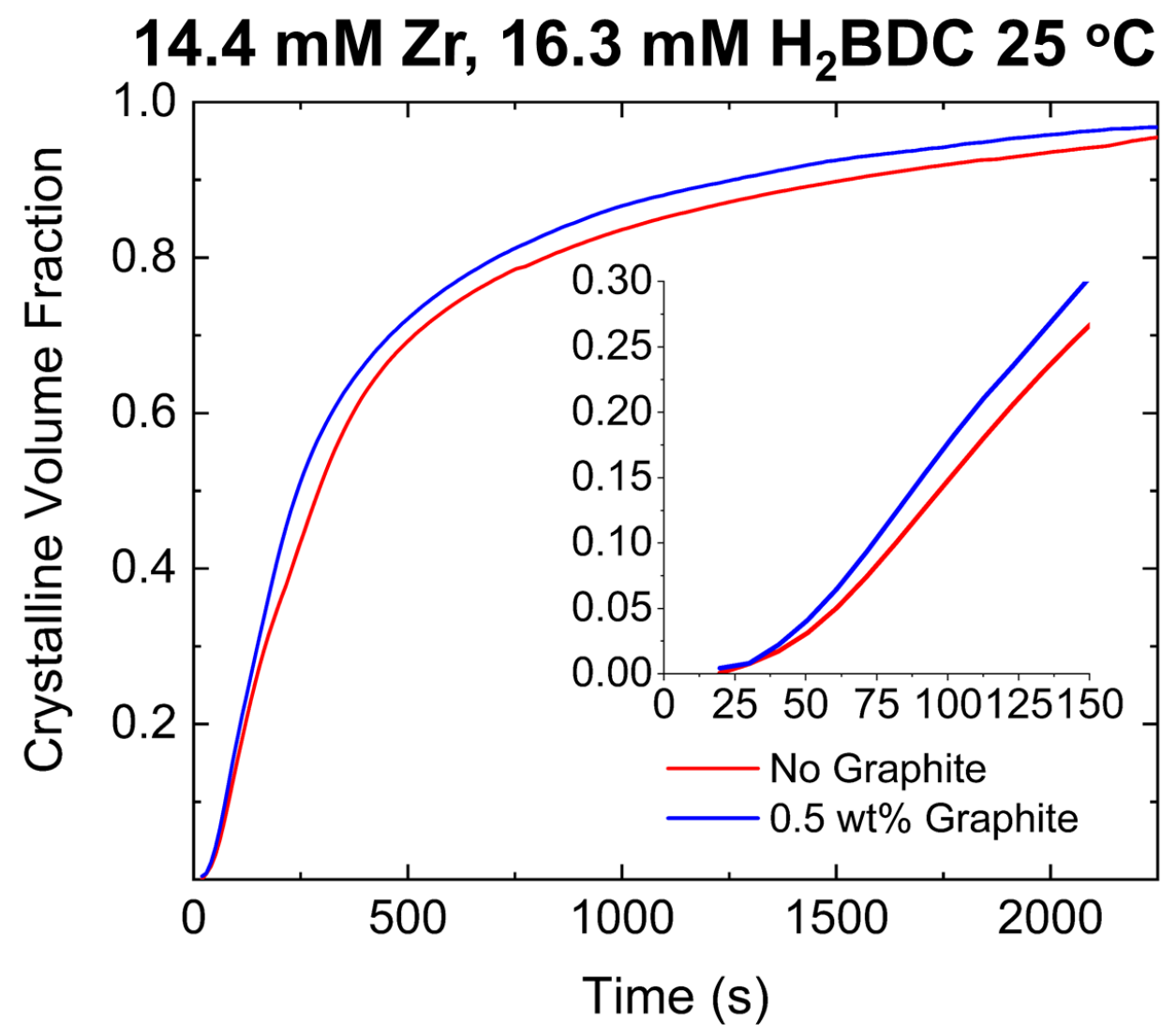

Figure S23: Crystalline volume fraction as a function of time for reactions conditions of $14.4 \mathrm{mM}$ $\mathrm{Zr}, 16.3 \mathrm{mM} \mathrm{H}_{2} \mathrm{BDC}$ at $25{ }^{\circ} \mathrm{C}$ with no graphite and the addition of $0.5 \mathrm{wt} \%$ graphite wrt solution. Inset shows the early time points of the reaction with marginal differences in the early-stage crystallization. 

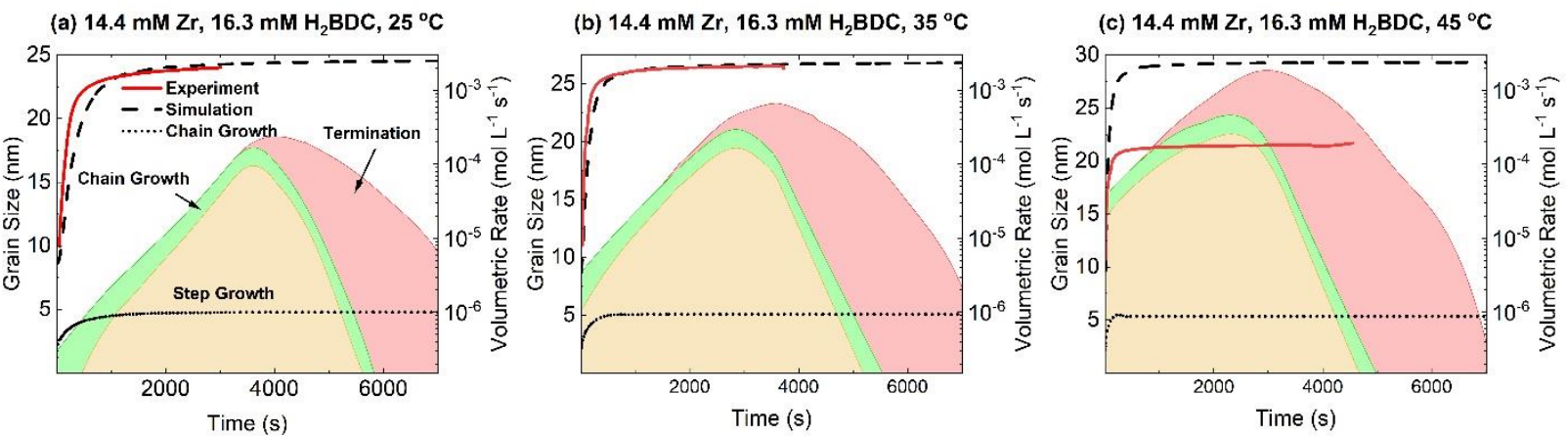

Figure S24: Theoretical and experimental grain sizes as a function of temperature with colormap showing the volumetric rates. (a) $14.4 \mathrm{mM} \mathrm{Zr}, 16.3 \mathrm{mM} \mathrm{H}_{2} \mathrm{BDC}, 25^{\circ} \mathrm{C}$, (b) $14.4 \mathrm{mM} \mathrm{Zr}, 16.3 \mathrm{mM}$ $\mathrm{H}_{2} \mathrm{BDC}, 35^{\circ} \mathrm{C}$, (c) $14.4 \mathrm{mM} \mathrm{Zr}, 16.3 \mathrm{mM} \mathrm{H} \mathrm{H}_{2} \mathrm{BDC}, 45^{\circ} \mathrm{C}$. The figure panel is the same as figure $3 \mathrm{a}-3 \mathrm{c}$ of the main manuscript with a linear $\mathrm{x}$-axis. 


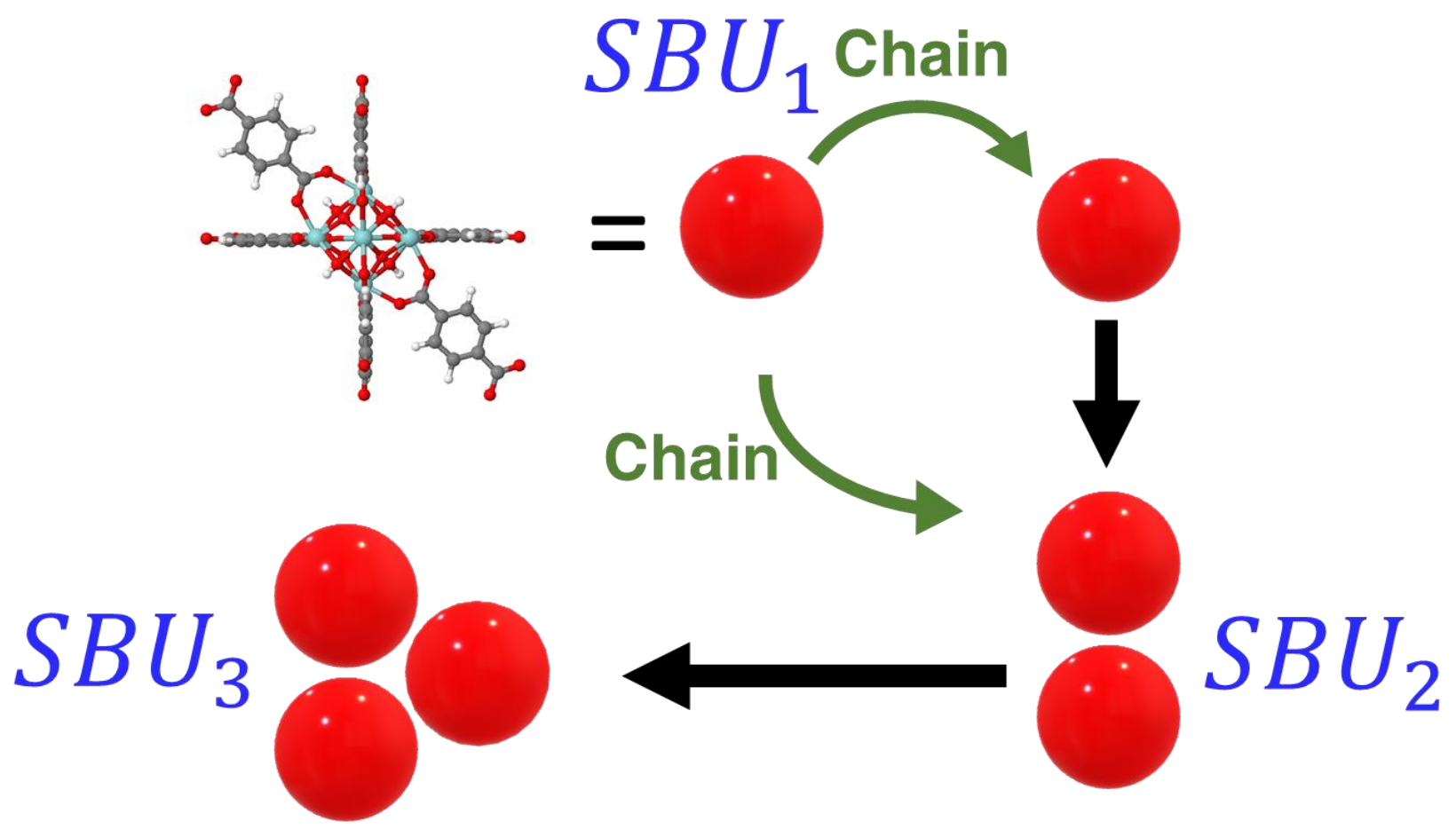

Figure S25: Chain growth mechanism 

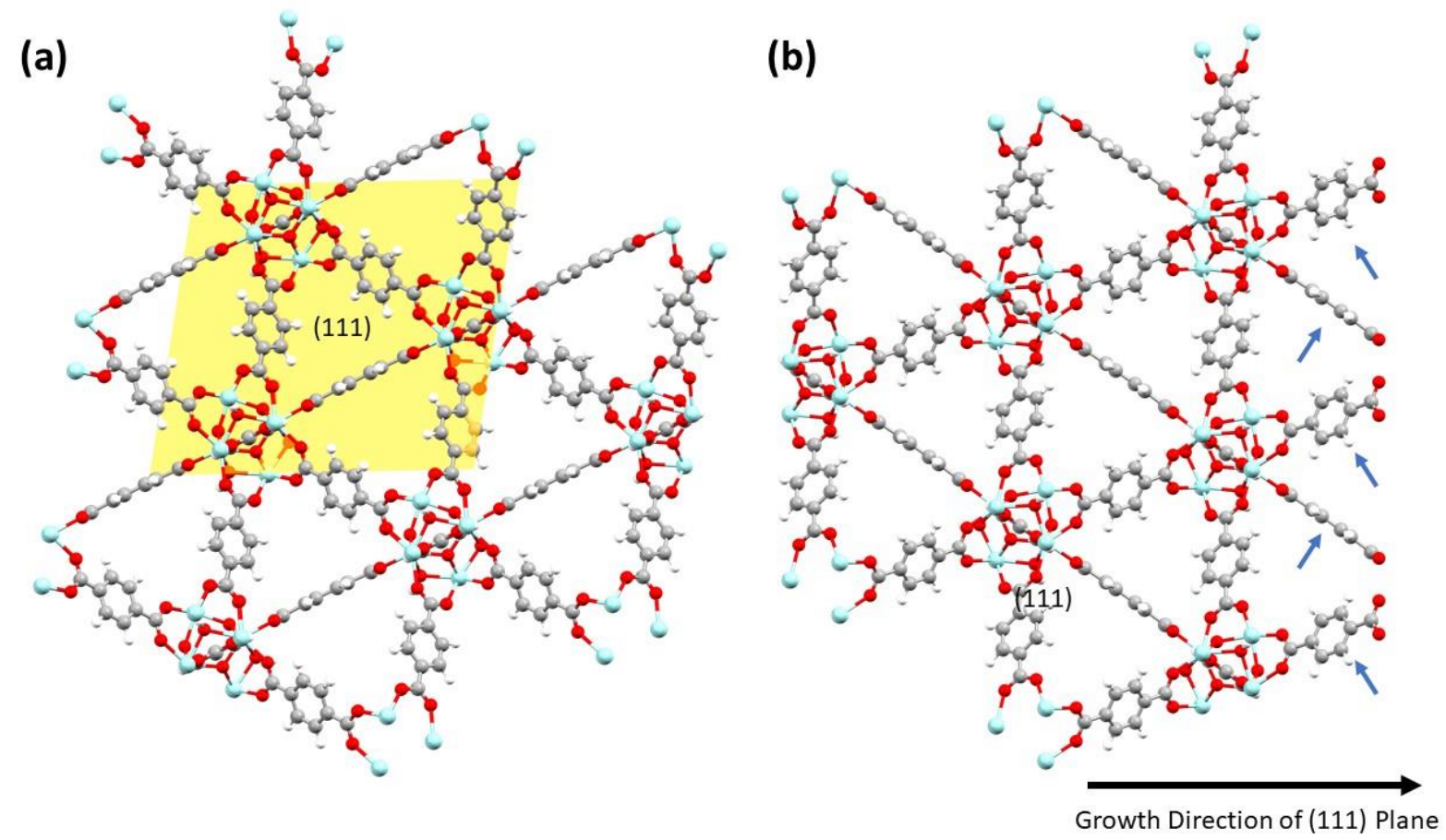

Figure S26: (111) plane of UiO-66 lattice. (a) Top view. (b) Side view showing the growth direction and exposed linkers on the growth surface. 


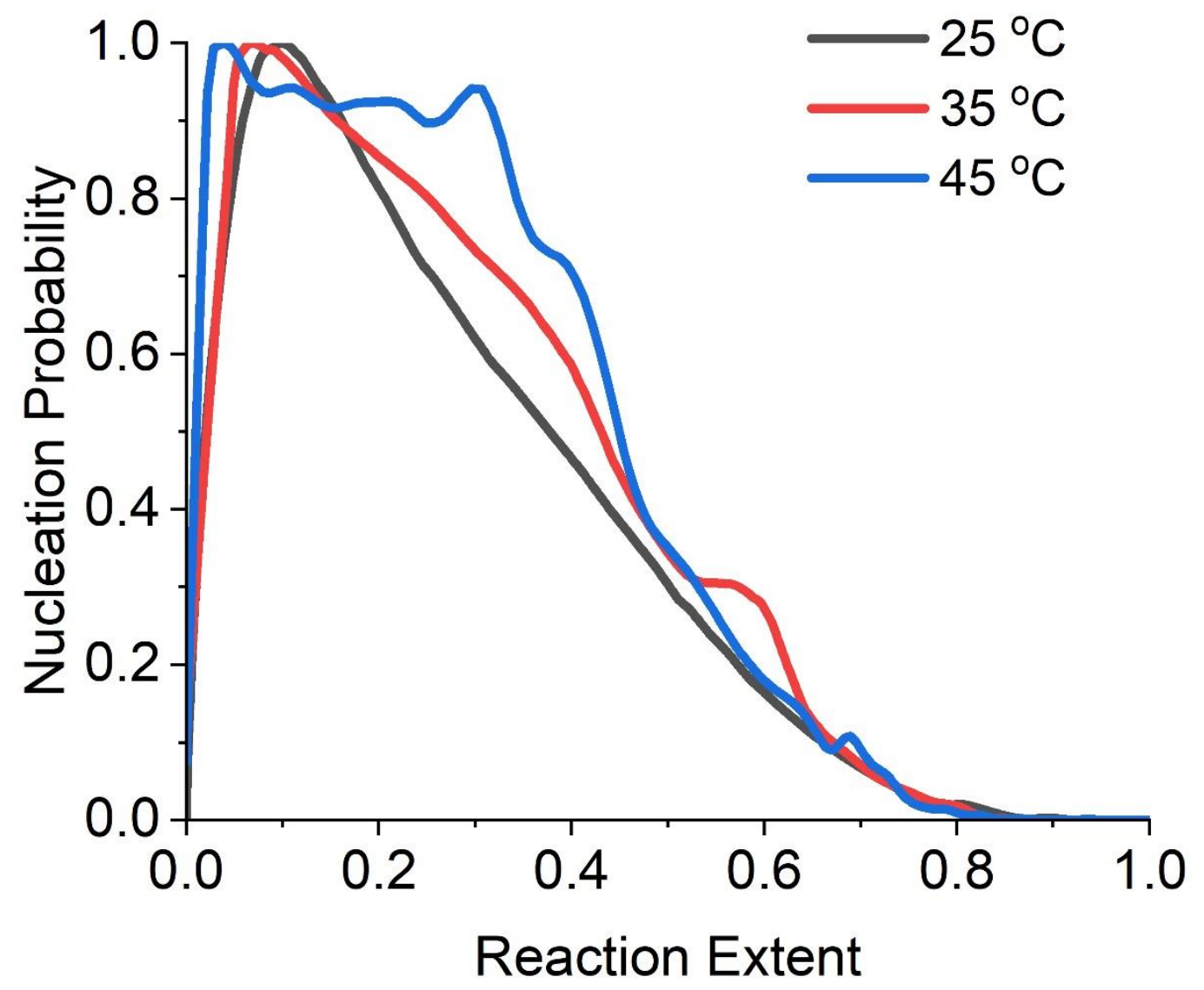

Figure S27: Normalized nucleation probabilities as a function of temperature obtained using theoretical model analogous to Gualtieri nucleation probabilities shown in Figure 4a of the main manuscript. 


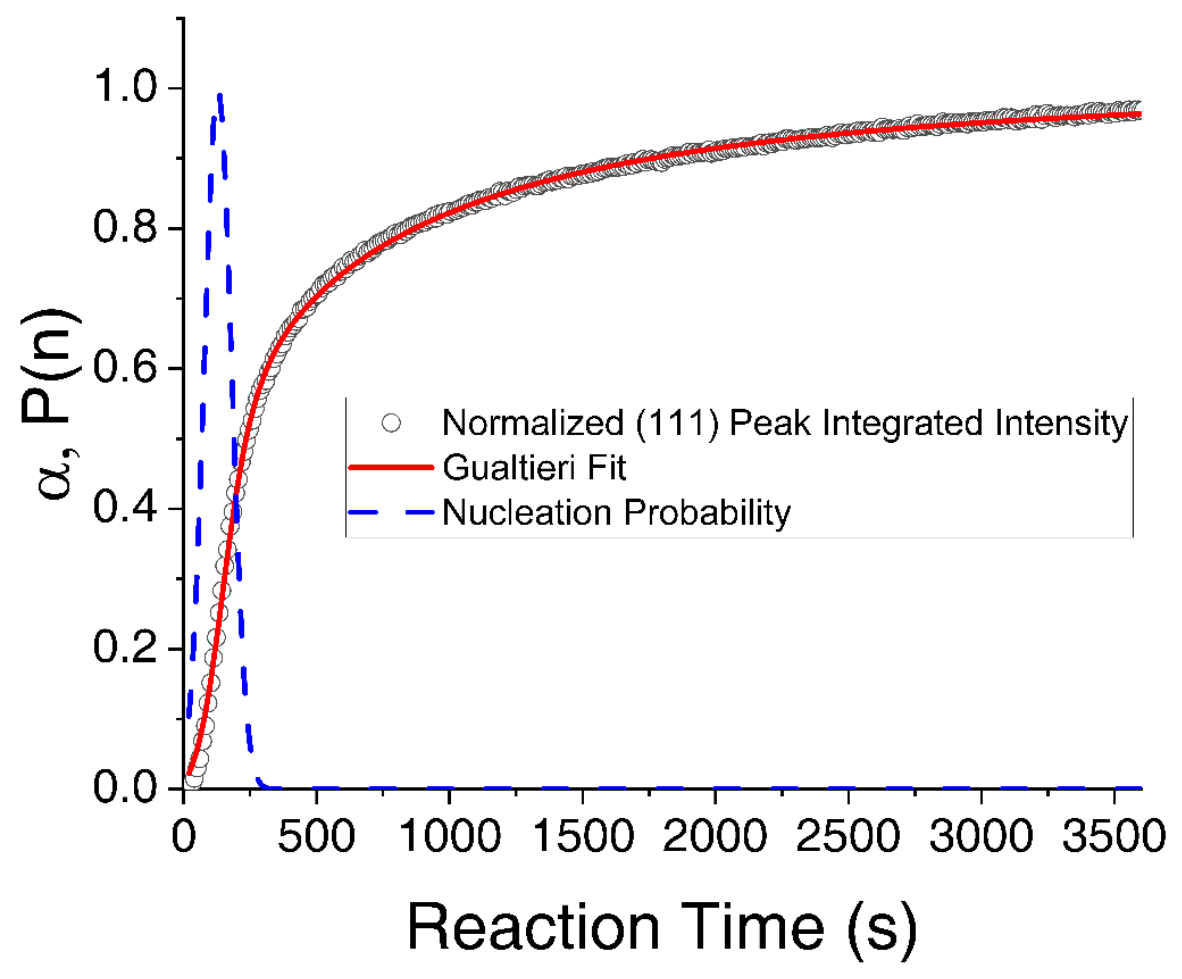

Figure S28: Gualtieri fitting of the (111) development over time with the nucleation probability calculated from Gualtieri fitting parameters for $14.4 \mathrm{mM} \mathrm{Zr}, 16.3 \mathrm{mM} \mathrm{H} 2 \mathrm{BDC}, 3.2 \mathrm{M} \mathrm{Ac}, 25{ }^{\circ} \mathrm{C}$. 


\begin{tabular}{|c|c|c|c|c|}
\hline In-situ WAXS experiments & $\begin{array}{l}\text { Microkinetic model } \\
\text { development }\end{array}$ & $\begin{array}{l}\text { Validation of the } \\
\text { microkinetic model }\end{array}$ & $\begin{array}{l}\text { Predictions using } \\
\text { microkinetic model }\end{array}$ & $\begin{array}{l}\text { Analysis of MOF synthesis } \\
\text { mechanism }\end{array}$ \\
\hline$\longrightarrow \begin{array}{c}\text { Prepare solutions } \\
\text { with various initial } \\
\text { concentration of } \\
\text { reactants (S1) }\end{array}$ & $\begin{array}{l}\text { Verify autocatalytic initiation } \\
\text { mechanism based on the } \\
\text { sigmoidal curve (S3) }\end{array}$ & $\begin{array}{l}\text { FT-IR analysis to validate the } \\
\text { autocatalysis assumption based on } \\
\text { the consumption of the reactants } \\
\text { (58) }\end{array}$ & $\begin{array}{l}\text { Predict crystalline fraction and } \\
\text { grain size for the experimental } \\
\text { data that is not used for } \\
\text { validation (S7) }\end{array}$ & $\begin{array}{c}\text { Compare the microkinetic model } \\
\text { against Gualtieri model (S10) } \\
\downarrow\end{array}$ \\
\hline $\begin{array}{c}\text { Choose operating } \\
\text { temperature }\end{array}$ & $\begin{array}{l}\text { Verify chain addition } \\
\text { (classical) and step } \\
\text { growth (non-classical) } \\
\text { mechanism (S3) }\end{array}$ & $\begin{array}{l}\text { Semi-classical double-well approach } \\
\text { to further validate autocatalysis (S8) }\end{array}$ & $\begin{array}{l}\text { Obtain the predicted and initial } \\
\text { numbers of the surface linkers and } \\
\text { verify the linear relationship }\end{array}$ & $\begin{array}{l}\text { Obtain graphs of the reaction } \\
\text { extent at the nucleation onset to } \\
\text { analyze the nucleation mechanism } \\
\text { (S5) }\end{array}$ \\
\hline $\begin{array}{l}\text { Calculate grain size } \\
\text { using FWHM and } \\
\text { Scherrer equation (S9) }\end{array}$ & $\begin{array}{c}\downarrow \\
\text { Verify Flory's } \\
\text { approximation (S3) } \\
\downarrow\end{array}$ & $\begin{array}{l}\text { In-situ WAXS experiments with } \\
\text { graphite added to the solution to } \\
\text { check for the possibility of } \\
\text { heterogeneous nucleation (S8) } \\
\downarrow\end{array}$ & $\begin{array}{c}\text { Predict molar rate } \\
\text { contributions and } \\
\text { absolute volumetric } \\
\text { rates }\end{array}$ & $\begin{array}{l}\text { Obtain nucleation and } \\
\text { growth rate kernels } \\
\downarrow \\
\text { Obtain activation energies }\end{array}$ \\
\hline $\begin{array}{l}\text { Analyze features of the } \\
\text { results obtained (S2) }\end{array}$ & $\begin{array}{l}\text { Optimize the values of variables in } \\
\text { the model against some of the } \\
\text { experimental results and justify } \\
\text { Flory's approximation ( }(\mathrm{S} 4 \& \mathrm{S6} \text { ) }\end{array}$ & $\begin{array}{c}\text { Fit the number of surface linkers to the } \\
\text { initial number of linkers to validate } \\
\text { MACS }\end{array}$ & $\begin{array}{c}\downarrow \\
\text { Predict the steady-state } \\
\text { grain size distributions }\end{array}$ & $\begin{array}{c}\text { for various phases of MOF } \\
\text { synthesis using Arrhenius } \\
\text { plot }\end{array}$ \\
\hline Relevant figures in the MS: $\mathbf{2}$ and 5 & Relevant figures in the MS: $2,3,4,5$ & Relevant figures in the MS: $2,3,4,5$ & Relevant figures in the MS: $2,5,7$ & Relevant figures in the MS: $1,3,6,7$ \\
\hline Relevant figures in the S1: S1, S2, S3 & $\begin{array}{l}\text { Relevant figures in the S1: S4, S5, } \\
\mathrm{S6}, \mathrm{S} 13, \mathrm{~S} 14, \mathrm{~S} 15, \mathrm{~S} 16, \mathrm{S17}\end{array}$ & $\begin{array}{l}\text { Relevant figures in the S1: S18, S19, } \\
\text { S20, S21, S22, S23, S24 }\end{array}$ & Relevant figures in the S1: S24 & $\begin{array}{l}\text { Relevant figures in the S1: S7, S8, } \\
\mathrm{S9}, \mathrm{S} 10, \mathrm{~S} 11, \mathrm{~S} 12, \mathrm{~S} 26, \mathrm{~S} 27, \mathrm{~S} 28\end{array}$ \\
\hline
\end{tabular}

Figure S29: Flow of the work presented in this study. 
Table S1. List of parameters used in the microkinetic model

\begin{tabular}{|c|c|c|c|c|c|c|}
\hline $\begin{array}{l}\# \text { (only free } \\
\text { parameters } \\
\text { are } \\
\text { counted) }\end{array}$ & $\begin{array}{l}\text { Initial } \\
\text { Concentration } \\
\text { of Metal } \\
\text { Cluster (mM) }\end{array}$ & $\begin{array}{l}\text { Initial } \\
\text { Concentration } \\
\text { of Organic } \\
\text { Linker (mM) }\end{array}$ & $\begin{array}{l}\text { Temperature } \\
\left({ }^{\circ} \mathrm{C}\right)\end{array}$ & Parameter & Value & Description \\
\hline \multirow[t]{2}{*}{1} & Any & Any & 25 & $a$ & 1.2 & Error minimized \\
\hline & Any & Any & 35,45 & $a$ & 1.2 & Prediction \\
\hline \multirow[t]{2}{*}{2} & Any & Any & 25 & $b$ & 1.8 & Error minimized \\
\hline & Any & Any & 35,45 & $b$ & 1.8 & Prediction \\
\hline \multirow[t]{5}{*}{3} & 14.4 & 16.3 & 25 & $k_{1}=k_{1} \alpha$ & 2700 & Error minimized \\
\hline & 14.4 & 16.3 & 35 & $k_{1}$ & 5400 & Error minimized \\
\hline & 14.4 & 16.3 & 45 & $k_{1}$ & 10339.2 & $\begin{array}{l}\text { Arrhenius } \\
\text { relationship } \\
\text { (prediction) }\end{array}$ \\
\hline & 28.8 or 7.15 & 16.3 & 25 & $k_{1}$ & 2700 & $\begin{array}{l}\text { Arrhenius } \\
\text { relationship } \\
\text { (prediction) }\end{array}$ \\
\hline & 14.4 & 8.15 & 25 & $k_{1}$ & 2700 & $\begin{array}{l}\text { Arrhenius } \\
\text { relationship } \\
\text { (prediction) }\end{array}$ \\
\hline \multirow[t]{5}{*}{4} & 14.4 & 16.3 & 25 & $k_{2}$ & 18000 & Error minimized \\
\hline & 14.4 & 16.3 & 35 & $k_{2}$ & 85000 & $\begin{array}{l}\text { Error } \\
\text { Minimized }\end{array}$ \\
\hline & 14.4 & 16.3 & 45 & $k_{2}$ & $3.6407 \times 10^{5}$ & $\begin{array}{l}\text { Arrhenius } \\
\text { relationship } \\
\text { (prediction) }\end{array}$ \\
\hline & 28.8 or 7.15 & 16.3 & 25 & $k_{2}$ & 18000 & $\begin{array}{l}\text { Arrhenius } \\
\text { relationship } \\
\text { (prediction) }\end{array}$ \\
\hline & 14.4 & 8.15 & 25 & $k_{2}$ & 18000 & $\begin{array}{l}\text { Arrhenius } \\
\text { relationship } \\
\text { (prediction) }\end{array}$ \\
\hline \multirow[t]{5}{*}{5} & 14.4 & 16.3 & 25 & $n_{k}$ & 700 & Error minimized \\
\hline & 14.4 & 16.3 & 35,45 & $n_{k}$ & 700 & $\begin{array}{l}\text { Predicted using } \\
\text { linker to surface } \\
\text { SBU ratio }\end{array}$ \\
\hline & 7.2 & 16.3 & 25 & $n_{k}$ & 3300 & Error minimized \\
\hline & 14.4 & 8.15 & 25 & $n_{k}$ & 45000 & Error minimized \\
\hline & 28.8 & 16.3 & 25 & $\overline{n_{k}}$ & 180 & $\begin{array}{l}\text { Predicted using } \\
\text { linker to surface } \\
\text { SBU ratio }\end{array}$ \\
\hline \multirow[t]{2}{*}{6} & 14.4 & 16.3 & 25 & $\alpha$ & 9000 & \\
\hline & 14.4 & 16.3 & 25 & $\alpha$ & 9000 & \\
\hline
\end{tabular}




\begin{tabular}{|l|l|l|l|l|l|l|}
\hline & 14.4 & 16.3 & 45 & $\alpha$ & 9000 & Prediction \\
\cline { 2 - 7 } & 28.8 or 7.15 & 16.3 & 25 & $\alpha$ & 9000 & Prediction \\
\cline { 2 - 6 } & 14.4 & 8.15 & 25 & $\alpha$ & 9000 & Prediction \\
\hline & Any & Any & Any & $m$ & 6 & $\begin{array}{l}\text { Based on the } \\
\text { crystal structure }\end{array}$ \\
\hline & Any & Any & Any & $l$ & 6 & $\begin{array}{l}\text { Based the } \\
\text { crystal structure }\end{array}$ \\
\hline
\end{tabular}


Table S2: Crystal Size at the Onset of Crystal Volume Fraction

\begin{tabular}{|l|l|l|l|l|l|}
\hline $\begin{array}{l}\text { Initial } \\
\text { Concentration } \\
\text { of } \begin{array}{c}\text { Metal } \\
\text { Cluster }(\mathrm{mM})\end{array}\end{array}$ & $\begin{array}{l}\text { Initial } \\
\text { Concentration } \\
\text { of Organic } \\
\text { Linker (mM) }\end{array}$ & $\begin{array}{l}\text { Temperature } \\
\left({ }^{\circ} \mathrm{C}\right)\end{array}$ & $\begin{array}{l}\text { Crystal Size } \\
\text { at the Onset } \\
\text { of } \\
\text { Crystalline } \\
\text { Volume } \\
\text { Fraction } \\
(\mathrm{nm})\end{array}$ & $\begin{array}{l}\text { Crystalline } \\
\text { Volume } \\
\text { Fraction }\end{array}$ & Description \\
\hline 14.4 & 16.3 & 25 & 8.67 & $2.84 \mathrm{e}-8$ & $\begin{array}{l}\text { Estimation } \\
\text { case to } \\
\text { obtain } \\
\text { critical } \\
\text { crystalline } \\
\text { volume } \\
\text { fraction }\end{array}$ \\
\hline 14.4 & & & & & \\
\hline 14.4 & 16.3 & 35 & 8.79 & $2.84 \mathrm{e}-8$ & \\
\hline 7.2 & 16.3 & 45 & 8.92 & $2.84 \mathrm{e}-8$ & \\
\hline 14.4 & 16.3 & 25 & 8.72 & $2.84 \mathrm{e}-8$ & \\
\hline
\end{tabular}


Table S3: Comparison of induction times between Gualtieri model and theoretical model

\begin{tabular}{|l|l|l|l|}
\hline $\begin{array}{l}\text { Metal Conc. } \\
(\mathbf{m M})\end{array}$ & $\begin{array}{l}\text { Linker Conc. } \\
(\mathbf{m M})\end{array}$ & Temp. $\left({ }^{\mathbf{O}} \mathbf{C}\right)$ & $\begin{array}{l}\text { Gualtieri } \\
\text { Induction Time, } \\
\boldsymbol{a}(\mathbf{s})\end{array}$ \\
\hline $14.4 \quad 0.5$ & 16.3 & 25 & $146 \pm 20$ \\
\hline $\begin{array}{l}14.4 \text { (with graphite) } \\
\text { wt\% grap }\end{array}$ & 25 & 110 \\
\hline 7.2 & 16.3 & 25 & 395 \\
\hline 14.4 & 16.3 & 35 & 63 \\
\hline 14.4 & 16.3 & 45 & 20 \\
\hline 14.4 & 8.15 & 25 & 1622 \\
\hline
\end{tabular}


Table S4: Gualtieri Fitting Parameters for experimental conditions used in the study. Multiple trials of the base condition were run to understand potential experimental variability.

\begin{tabular}{|l|l|l|l|l|l|l|l|ll|}
\hline & & \multicolumn{7}{|c|}{ Gualtieri Fitting Parameters } & \multicolumn{2}{|l|}{} \\
\hline $\begin{array}{l}\text { Zr Conc } \\
(\mathrm{mM})\end{array}$ & $\begin{array}{l}\mathrm{H}_{2} \mathrm{BDC} \\
\text { Conc }(\mathrm{mM})\end{array}$ & $\begin{array}{l}\text { Temp } \\
\left({ }^{\circ} \mathrm{C}\right)\end{array}$ & $\mathrm{a}(\mathrm{s})$ & $\mathrm{b}(\mathrm{s})$ & $\mathrm{kg}(1 / \mathrm{s})$ & $\mathrm{n}$ & $\mathrm{kn}(1 / \mathrm{s})$ & Comment \\
\hline 14.4 & 16.3 & 25 & 172 & 57 & $2.10 \mathrm{E}-03$ & 0.6 & $5.83 \mathrm{E}-03$ & Trial 1 & \\
\hline 14.4 & 16.3 & 25 & 130 & 50 & $2.74 \mathrm{E}-03$ & 0.6 & $7.68 \mathrm{E}-03$ & Trial 2 & \\
\hline 14.4 & 16.3 & 25 & 152 & 53 & $2.62 \mathrm{E}-03$ & 0.7 & $6.58 \mathrm{E}-03$ & Trial 3 & \\
\hline 14.4 & 16.3 & 25 & 129 & 51 & $2.94 \mathrm{E}-03$ & 0.5 & $7.76 \mathrm{E}-03$ & Trial 4 & \\
\hline & & & 110 & 42 & $2.88 \mathrm{E}-03$ & 0.7 & $9.07 \mathrm{E}-03$ & $\begin{array}{l}\text { wt\% } \\
\text { added }\end{array}$ & graphite \\
\hline 14.4 & 16.3 & 25 & & & & & & \\
\hline 14.4 & 16.3 & 35 & 62 & 29 & $7.28 \mathrm{E}-03$ & 0.4 & $1.60 \mathrm{E}-02$ & & \\
\hline 14.4 & 16.3 & 45 & 20 & 15 & $2.14 \mathrm{E}-02$ & 0.4 & $5.11 \mathrm{E}-02$ & & \\
\hline 14.4 & 8.15 & 25 & 1622 & 574 & $2.40 \mathrm{E}-04$ & 1.4 & $6.17 \mathrm{E}-04$ & & \\
\hline 7.2 & 16.3 & 25 & 395 & 112 & $1.50 \mathrm{E}-03$ & 0.7 & $2.53 \mathrm{E}-03$ & & \\
\hline
\end{tabular}




\section{References:}

1. DeStefano MR, Islamoglu T, Hupp JT, Farha OK. Room-Temperature Synthesis of UiO66 and Thermal Modulation of Densities of Defect Sites. Chem Mater 2017, 29(3): 13571361.

2. Klug HP, Alexander L, Kummer E. X-ray diffraction analysis of crystalline dusts. J Ind Hyg Toxicol 1948, 30(3): 166-171.

3. Ragon F, Campo B, Yang Q, Martineau C, Wiersum AD, Lago A, et al. Acidfunctionalized UiO-66(Zr) MOFs and their evolution after intra-framework cross-linking: structural features and sorption properties. J Mater Chem A 2015, 3(7): 3294-3309.

4. Ragon F, Horcajada P, Chevreau H, Hwang YK, Lee UH, Miller SR, et al. In Situ EnergyDispersive X-ray Diffraction for the Synthesis Optimization and Scale-up of the Porous Zirconium Terephthalate UiO-66. Inorganic Chemistry 2014, 53(5): 2491-2500.

5. Ragon F, Chevreau H, Devic T, Serre C, Horcajada P. Impact of the Nature of the Organic Spacer on the Crystallization Kinetics of UiO-66(Zr)-Type MOFs. Chemistry - A European Journal 2015, 21(19): 7135-7143.

6. Schoenecker PM, Belancik GA, Grabicka BE, Walton KS. Kinetics study and crystallization process design for scale-up of UiO-66-NH2 synthesis. Aiche J 2013, 59(4): 1255-1262.

7. Van Vleet MJ, Weng T, Li X, Schmidt JR. In Situ, Time-Resolved, and Mechanistic Studies of Metal-Organic Framework Nucleation and Growth. Chemical Reviews 2018, 118(7): 3681-3721.

8. Laurence RL, Galvan R, Tirrell MV. Mathematical modelling of polymerization kinetics. In: McGreavy C (ed). Polymer Reactor Engineering. Springer Netherlands: Dordrecht, 1994, pp 87-124.

9. Shustorovich E. Metal-surface reaction energetics: theory and applications to heterogeneous catalysis, chemisorption, and surface diffusion. VCH Publishers, Inc, 220 East 23 rd St, Suite 909, New York, New York 10010, USA, 19912391991.

10. Shustorovich E. Energetics of metal-surface reactions: back-of-the-envelope theoretical modeling. Journal of Molecular Catalysis 1989, 54(3): 301-311. 
11. Dighe AV, Singh MR. Solvent fluctuations in the solvation shell determine the activation barrier for crystal growth rates. Proc Natl Acad Sci U S A 2019, 116(48): 23954-23959.

12. Bristow JK, Tiana D, Walsh A. Transferable Force Field for Metal-Organic Frameworks from First-Principles: BTW-FF. J Chem Theory Comput 2014, 10(10): 4644-4652.

13. Allinger NL, Yuh YH, Lii JH. Molecular Mechanics - the Mm3 Force-Field for Hydrocarbons .1. Journal of the American Chemical Society 1989, 111(23): 8551-8566.

14. Bristow JK, Svane KL, Tiana D, Skelton JM, Gale JD, Walsh A. Free Energy of Ligand Removal in the Metal-Organic Framework UiO-66. J Phys Chem C 2016, 120(17): 92769281.

15. Langford JI, Wilson AJC. Scherrer after sixty years: A survey and some new results in the determination of crystallite size. Journal of Applied Crystallography 1978, 11(2): 102-113.

16. Gualtieri AF. Synthesis of sodium zeolites from a natural halloysite. Phys Chem Miner 2001, 28(10): 719-728. 